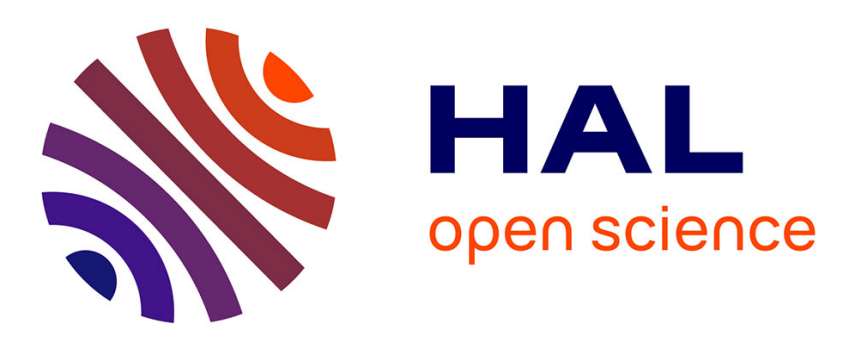

\title{
The relationship between intraseasonal tropical variability and ENSO and its modulation at seasonal to decadal timescales
}

\author{
D. Gushchina, B. Dewitte
}

\section{- To cite this version:}

D. Gushchina, B. Dewitte. The relationship between intraseasonal tropical variability and ENSO and its modulation at seasonal to decadal timescales. Central European Journal of Geosciences, 2011, 3 (2), pp.175-196. 10.2478/s13533-011-0017-3 . hal-00994186

\section{HAL Id: hal-00994186 \\ https://hal.science/hal-00994186}

Submitted on 22 May 2014

HAL is a multi-disciplinary open access archive for the deposit and dissemination of scientific research documents, whether they are published or not. The documents may come from teaching and research institutions in France or abroad, or from public or private research centers.
L'archive ouverte pluridisciplinaire HAL, est destinée au dépôt et à la diffusion de documents scientifiques de niveau recherche, publiés ou non, émanant des établissements d'enseignement et de recherche français ou étrangers, des laboratoires publics ou privés. 


\title{
The relationship between intraseasonal tropical variability and ENSO and its modulation at seasonal to decadal timescales
}

Research Article

\author{
Daria Gushchina1*, Boris Dewitte ${ }^{2}$ \\ 1 Moscow State University, Geographical Faculty, Leninskie gory, 119991, Moscow, Russia \\ 2 Laboratoire d'Etudes en Géophysique et Océanographie Spatiale, 14, av. Ed. Belin, Toulouse, 31400, France
}

Received 9 March 2011 ; accepted 4 May 2011

\begin{abstract}
The intraseasonal tropical variability (ITV) patterns in the tropical troposphere are documented using double space-time Fourier analysis. Madden and Julian oscillations (MJO) as well as equatorial coupled waves (Kelvin and Rossby) are investigated based on the NCEP/NCAR Reanalysis data for the 1977-2006 period and the outputs of an intermediate ocean-atmosphere coupled model named LODCA-OTCM. A strong seasonal dependence of the ITV/ENSO relationship is evidenced. The leading relationship for equatorial Rossby waves (with the correlation of the same order than for the MJO) is documented; namely, it is shown that intensification of Rossby waves in the central Pacific during boreal summer precedes by half a year the peak of El Niño. The fact that MJO activity in spring-summer is associated to the strength of subsequent El Niño is confirmed. It is shown that LODCA-QTCM is capable of simulating the convectively coupled equatorial waves in outgoing long wave radiation and zonal wind at $850 \mathrm{hPa}$ fields with skill comparable to other Coupled General Circulation Models. The ITV/ENSO relationship is modulated at low frequency. In particular the periods of low ENSO amplitude are associated with weaker MJO activity and a cancellation of MJO at the ENSO development phase. In opposition, during the decaying phase, MJO signal is strong. The periods of strong ENSO activity are associated with a marked coupling between MJO, Kelvin and equatorially Rossby waves and ENSO; the precursor signal of MJO (Rossby waves) in the western (central) Pacific is obvious. The results provide material for the observed change in ENSO characteristics in recent years and question whether the characteristics of the ITV/ENSO relationship may be sensitive to the observed warming in the central tropical Pacific.
\end{abstract}

Keywords: ocean-atmosphere interaction • El Niño Southern Oscillation • intraseasonal tropical variability

(C) Versita Sp. z o.o.

\section{Introduction}

It is well known that a large part of the synoptic variability in the tropics is due to propagating disturbances moving

*E-mail: dasha155@mail.ru parallel to the equator. Such disturbances are characterized by the time scales from several days up to seasons and so on, representing the tropical intraseasonal variability (ITV). The tropical intraseasonal variability was shown to play an important role in ENSO forcing as well as in ENSO teleconnections $[54,58]$.

In the intraseasonal variability, one usually distinguishes 
two modes: the so-called coherent Madden-Julian oscillations with frequencies in the 30 to 90 days $^{-1}$ band and zonal wave numbers of 1 to 3 [46] and the equatorial convectively coupled waves [81, hereafter WK99] that may be interpreted as a stochastic mode relative to slow oceanic processes. The MJO is the dominant tropical intraseasonal mode and a key source of untapped predictability in both the tropics and extra-tropics, e.g. WK99 $[61,76,77,82]$. The MJO significantly affects a wide range of tropical weather such as the onset and break-off of the Indian and Australian summer monsoons [85, 86], and the formation of tropical cyclones [43, 49]. Being a strong tropical heating source through its impacts on large-scale convection, the MJO also drives teleconnections to the extra-tropics $[6,78,80]$. On a longer timescale, the MJO is thought to play a crucial role in the triggering of $\mathrm{El}$ Niño events, e.g. $[7,34,70]$. Therefore, the MJO is important for both weather and climate prediction. However the MJO is usually poorly simulated by General Circulation Models [45]. Typically, model MJOs are too weak and propagate too fast, e.g. [27, 28, 40,67].

Because of increases in MJO activity in the vicinity of the equator in boreal spring and because the ENSO onset tends to occur in spring-early summer, many recent investigations were devoted to the relationships between MJO and ENSO, suggesting a possible mechanism of interaction between both signals at seasonal timescale. In particular, the development of some recent El Niños was suggested to be related to the enhanced MJO activity in the western Pacific observed some months before the peak phase of El Niño, e.g. [34, 39, 51, 79, 93]. The MJO has both an impact in the momentum and the heat flux forcing to the ocean. The positive phase of the MJO contributes to the eastward migration of westerly wind stress anomalies that can force equatorial Kelvin waves $[15,34,58]$. The latter impact the central equatorial Pacific through zonal advection near the eastern edge of the warm pool $[7,42,65]$ and propagate eastward, resulting in the warming of the eastern tropical Pacific $[31,93]$. The MJO also cools the western Pacific by increasing the oceanatmosphere heat flux and upper-ocean mixing. Both processes contribute to decrease the east-west temperature gradient, which results in westerly wind anomalies in this region and in turn contributes to the propagation of the warm pool to the east. This warm pool shift was suggested to trigger the El Niño onset [56]. The opposite mechanism promotes the development of La Niña conditions [39]. Noteworthy the MJO induces easterly anomalies that might interact with ENSO: in [59, 62-64], it was shown that intraseasonal spatial patterns associated with the MJO might weaken El Niño or amplify La Niña, while other patterns might amplify El Niño. These associations occur because the easterly and westerly phases of the MJO evolve differently relative to each other during different ENSO states (see [59]). Particularly during the El Niño developing phase the interaction between the background westerlies and MJO associated wind anomalies results in strong westerly anomalies which in turn enhance the atmospheric forcing of the ocean.

Whereas there is more and more evidence that the $\mathrm{MJO}$ can rectify an ENSO [35], there is remaining difficulties in diagnosing a clear relationship between MJO and ENSO when focusing on the mature phase of the MJO activity. For instance, Hendon et al. [30] and Slingo et al. [68] noticed a weak correlation between MJO and ENSO during the boreal winter, i.e. when MJO is strongest in the Southern Hemisphere. Both studies do not distinguish the seasons and take into account all months of the year in their correlation analysis. In fact, because of the eastward propagation of the MJO related fields, MJO is supposed to be critical for ENSO onset in spring-summer, i.e. when it is weaker but still observed. Moreover in spring, MJO occurs near the equator, which favors the forcing of the equatorial oceanic Kelvin wave by westerly wind anomalies $[60,92]$.

When the globally averaged MJO is considered, the relationships with ENSO may be nothing more than the signature of the modulation of $\mathrm{MJO}$ resulting from the highest SST shifts toward the date line once El Niño has started e.g. $[5,18,88]$. However $[7,20,30,58]$ demonstrated that expansion of the eastward extent of the MJO across the Pacific during the developing El Niño occurs more often than a simple eastward extension. To prove the critical role of $\mathrm{MJO}$ in triggering $\mathrm{El} \mathrm{Niño,} \mathrm{Hendon} \mathrm{et} \mathrm{al.} \mathrm{[29]}$ emphasized the role of MJO activity in the western $\mathrm{Pa}$ cific near its source region. In particular, they revealed an important seasonal dependence on the lagged association of the MJO with ENSO. They also suggest that the seasonally varying relationship between MJO activity and the ENSO cycle might be anticipated due to the marked seasonal cycle of the MJO activity and phaselocking of ENSO onset to the seasonal cycle. They further argued that the causative relationship between enhanced spring/early summer MJO activity and El Niño in autumn/winter stems from the association of enhanced MJO activity with anomalous surface westerlies in the western Pacific. Spring is when the mean equatorial zonal SST gradient in the Pacific is the weakest and the center of MJO activity has moved towards the equator. The opposite relationship with the development of La Niña tends to hold as well which makes the MJO a potential contributor to the ENSO asymmetry [1]. Presumably, years with less-than normal MJO activity exhibit an easterly anomaly while years with above-normal MJO activity ex- 
hibit a westerly anomaly. However the MJO can also generate easterly anomalies during its suppressed convective phase, and these easterlies alternate with MJO westerlies. Further, periods of enhanced local MJO activity across the west Pacific are likely also periods when the regional SST is higher than average. This pattern tends to be associated with enhanced low level westerly winds to the west of the SST maximum, even ignoring the MJO. So, such low frequency low-level westerlies and enhancement of the MJO might occur coincidentally because both are modulated by the same warm background state. These observations stress the important role of the ocean background state in controlling the evolution and characteristics of the intraseasonal oscillations in the equatorial Pacific [59]. It calls for a detailed investigation of such processes of interaction in long-term data sets. Due to its likely coupled nature $[20,58,59]$, the analysis of coupled models simulations may provide useful material for understanding the role of the MJO activity in modifying the ENSO properties. However, the changes in the evolution of intraseasonal variations such as the MJO during the course of ENSO [59] might feedback upon the interannual mode to influence the evolution of ENSO itself.

Here, we take advantage of the versatility of an intermediate coupled model of the tropical Pacific to study the coupling between the ITV and ENSO. Following [29], the focus is on the seasonal dependence of ITV and ENSO. It is beyond the scope of the paper to investigate the dependence of the ITV characteristics as a function of the ENSO phase although the latter can be influential on the amplitude and propagating characteristics of the MJO in particular [59]. However, whereas Hendon et al. [29] concentrates on the MJO activity, we also document all the components of the simulated and observed ITV, namely the variability associated to equatorial coupled waves observed in the tropical belt (Kelvin, equatorially Rossby, mixed Rossby gravity, westward and eastward propagating gravity waves). In that sense our study can be viewed as an extension of the study by Hendon et al. [29]. The reason for considering the full spectrum of the ITV is twofold: first, these equatorial waves also have a pronounced signature in precipitation [45], zonal wind, wind stress and net heat fluxes fields [26], potentially impacting the SST and therefore air-sea coupling. In particular, because of their propagation characteristics, these waves may interact with the mean atmospheric circulation in the region where El Niño can develop and impact the growth of the coupled instabilities. Second, this share of the ITV can act as a "noise-maker" for the tropical Pacific system and participate in the ENSO low frequency modulation, which we will diagnose in the intermediate coupled model used in this study.
The paper is organized as follows: first the data and the method for extracting the component of the ITV is presented. Then the intermediate coupled model is described. In section 4 , the ITV simulated by the coupled model is presented and analyzed, then the relationship between ITV and ENSO is discussed. Conclusions are provided in section 6 .

\section{Data and methods}

\section{Data}

The daily surface zonal wind and outgoing longwave radiation (OLR) were obtained from the National Center for Environmental Prediction-National Center for Atmospheric Research NCEP/NCAR reanalyses [32]. These fields are referred to as "observations" in the following although, strictly speaking, they are not observed data but results from a combination of observations and model simulations. The monthly Nino 3.4 SST anomalies are obtained from the U.S. Weather Service's Climate Prediction Center website (http://www.cpc.ncep.noaa.gov/ data/indices/).

\section{Space-time spectral analysis}

Similar method to WK99 is used. It is briefly described here. The reader is invited to refer to WK99 for further details. As demonstrated by WK99, the structure of convectively coupled equatorial waves is either symmetric or antisymmetric about the equator, in accordance with shallow water theory. A gridded field, D, that is a function of latitude, $\phi$, can be written as $\mathrm{D}(\phi)=\mathrm{DA}(\phi)+\mathrm{DS}(\phi)$, where $\mathrm{DA}(\phi)=[\mathrm{D}(\phi)-\mathrm{D}(-\phi)] / 2$ is the antisymmetric component, and $\mathrm{DS}(\phi)=[\mathrm{D}(\phi)+\mathrm{D}(-\phi)] / 2$ is the symmetric component. The model and observed fields are therefore decomposed into its antisymmetric and symmetric components. Then the frequency-wave number analysis is performed. Space-time spectra of daily data were obtained for the 30 years of model data and compared with those of 30 years of observations (1977-2006). To reduce the noise, the space-time spectra were calculated for successive overlapping segments of data and then averaged. Here 96-day long segments with a 30-day overlap between each segment were used following WK99. Complex FFTs are performed in longitude to obtain Fourier coefficients (in zonal planetary wavenumber space) for each time and latitude. Further complex FFTs are applied in time to these coefficients to obtain the wavenumberfrequency spectrum for each latitude. Finally, the data set power is averaged over all available segments of the 96 days, and is further summed up for the latitudes be- 
tween $15^{\circ} \mathrm{S}$ and $15^{\circ} \mathrm{N}$. The resulting effective bandwidth is $1 / 48$ cycles per day (cpd) in frequency, and 1 unit zonal wavenumber.

An estimate of the "background" space-time spectrum is obtained for each data set by averaging the power of the symmetric and antisymmetric spectra. A smoothing of the obtained series is then applied using a 1-2-1 filter in frequency and wavenumber successively eleven times (see WK99). The raw spectra are then divided by this background to obtain an estimate of the signal standing above the background noise. In WK99, power at 1.1 times the background or greater was deemed significant, based on a crude estimate of the degrees of freedom involved. In reality, a true estimate of the degrees of freedom is difficult to obtain due to the complications of simultaneous autocorrelation in both space and time. Here, since the data sets used are half the length of those used in WK99 (one time per day versus twice per days), we have chosen the threshold of 1.2 times (or 20\%) above the background as in [45]. Peaks standing above the background correspond to the Kelvin, $n=1$ equatorial Rossby (ER), mixed Rossby-gravity (MRG), n=0, 1 eastward inertio-gravity (EIG), $n=1$ westward inertio-gravity (WIG) waves.

\section{Isolating the MJO, Kelvin, ER, MRG, EIG and WIG signals}

In this paper, the definitions of MJO, Kelvin, ER, MRG, EIG and WIG modes are as in WK99, and the various contributions were isolated using the same method: each mode was isolated by filtering in the wavenumberfrequency domain (see Fig. 6 of WK99 for the definition of the regions in the frequency and wavenumber space domain for each wave), and the corresponding time series were obtained by an inverse space-time Fourier transform.

\section{Lag correlation analysis.}

The amplitude of equatorial waves was computed by taking the root mean square (rms) of the variance of MJO, Kelvin and $n=1-E R$-filtered U850 and OLR field, with the rms computed in a 3-month running window. Then the variance was sampled monthly to the central month. Hence, for example, the MJO amplitude in February 1977 is the square root of the mean variance of MJO-filtered U850 and OLR computed over January-March 1977. Then these amplitude time series were equatorially averaged $\left(5^{\circ} \mathrm{S}-5^{\circ} \mathrm{N}\right)$ at each point of longitude. The equatorially averaged wave amplitude was further correlated with the January sea surface temperature average over the Nino 3.4 box $\left(5^{\circ} \mathrm{S}-5^{\circ} \mathrm{N} ; 170^{\circ} \mathrm{W}-120^{\circ} \mathrm{W}\right)$, hereafter referred to as the SST Nino 3.4 index. January was chosen as a month of the peak of El Niño. The analysis of this correlation (see below) emphasized that the strongest leading correlation with respect to SST Nino 3.4 for the MJO is observed in the Western Pacific; for the Kelvin wave, in the Eastern and Western Pacific; and for the Rossby wave, in the central Pacific. To explore carefully these relationships, we defined the indices of the wave's intensity. The wave's amplitude, computed as described above, was averaged over the following regions: Western Pacific: $5^{\circ} \mathrm{S}-5^{\circ} \mathrm{N} ; 120^{\circ}$ $180^{\circ} \mathrm{E}$, Central Pacific: $5^{\circ} \mathrm{S}-5^{\circ} \mathrm{N} ; 140^{\circ} \mathrm{E}-160^{\circ} \mathrm{W}$; Eastern Pacific: $5^{\circ} \mathrm{S}-5^{\circ} \mathrm{N} ; 160^{\circ}-100^{\circ} \mathrm{W}$. From here on, we will refer to these indices as named in Table 1.

Table 1. Indices of equatorial waves intensity

\begin{tabular}{cccc}
\hline Western Pacific & Central Pacific & Eastern Pacific \\
\hline OLR & $\begin{array}{c}\text { WPacMJO }_{O L R}, \\
\text { WPacKelvin }_{O L R}\end{array}$ & CPacER $_{O L R}$ & EPacKelvin $_{O L R}$ \\
\hline U850 & $\begin{array}{c}\text { WPacMJO }_{\cup 850} \\
\text { WPacKelvin }_{U 850}\end{array}$ & CPacERU $_{\cup 850}$ & EPacKelvin $_{\cup 850}$ \\
\hline
\end{tabular}

The lag correlation between the SST Nino 3.4 index (smoothed with a 3-month running mean to be consistent with the wave indices) and the above defined indices was computed.

\section{Model and experiments' descrip- tion}

\section{Model setup:}

The coupled model used in this study consists of a tropical Pacific linear ocean model and a global general circulation model of intermediate complexity. The atmosphere component is the QTCM model (for Quasi-Equilibrium Tropical Circulation Model) developed by the team of Prof. David Neelin at Los Angeles University. It is a primitive equation-based intermediate-level atmospheric model that focused on simulating the tropical atmosphere. The constraints placed on the flow by quasi-equilibrium parameterization are used to calculate typical vertical structures of temperature, moisture and winds. Being more complicated than a simple model, the model has full nonlinearity, includes a radiative-convective feedback package, and a simple land soil moisture routine. Topography is not taken explicitly into account but an inhomogeneous surface roughness is used. For its convective parameterization, this model uses the Betts-Miller moist convective scheme [8], a scheme which is also used in some General Circulation Models. Model formulation is described in [55] and model implementation is described in [91]. Zeng et al. 
[91] demonstrate that this intermediate-level model does a reasonable job in simulating tropical climatology and ENSO variability. The model also maintains intraseasonal oscillations which some of its characteristics resemble the real-world intraseasonal oscillations [22, 24, 44].

The ocean component is the LODCA model. The full description of the model is presented in $[13,16,23]$. Briefly, the circulation for the oceanic part is governed by adiabatic, linear shallow water wave dynamics. It includes three baroclinic modes with characteristics of phase speed $c_{n}$ and projection coefficient $P_{n}$, derived from the vertical mode decomposition of a mean density profile typical of the central Pacific. The friction $r_{\prime \prime}$ is also chosen as in [16, cf their Table 1]. A well-mixed surface layer of 50-m depth is embedded in the ocean model. SST anomalies are calculated from a fully nonlinear surface mixed layer temperature equation similar to equation (1) in [90], but different surface currents and upwelling climatologies are used, as well as a different parameterization of subsurface temperature.

The coupling between the ocean and the atmosphere is through the momentum fluxes (wind stress) and heat fluxes (evaporation) over the tropical Pacific $\left(130^{\circ} \mathrm{E}-80^{\circ} \mathrm{W}\right.$; $\left.20^{\circ} \mathrm{S}-20^{\circ} \mathrm{N}\right)$. Outside the tropical Pacific, the climatological Reynolds SST is prescribed. Since LODCA is an anomaly model, wind stress and heat flux anomalies need to be calculated at each time step. In order to derive daily anomalies, QTCM is first run in a climatological mode (i.e. using SST climatological forcing) during 30 years. The last simulated 20 years are used to derive a daily mean climatology for wind stress and heat flux. The latter is then prescribed in the coupled mode to derive the anomalous atmospheric fields to force LODCA. A coupling efficiency of 1.4 is used that allows for sustaining oscillations in the models and maintaining an unstable ENSO mode. Below these values, the simulated ENSO is stable and dissipation processes in the model lead to a damped interannual variability after 10 to 15 years of simulation.

The model simulates ENSO variability that shares many characteristics with observations $[14,21]$. In particular, the ENSO phase locking resembles the one of the observations with most simulated El Niño events occurring in Austral spring - Early summer. The ENSO modulation also has a realistic amplitude and timescale. As will be seen below, the ITV simulated by LODCA-QTCM is also comparable to the observations.

\section{Experiments}

A 250-year model run was carried out with LODCAQTCM starting from initial conditions corresponding to the $1^{\text {st }}$ of January 1980 . The simulation consists in run- ning the model with the set of parameters corresponding to the standard values of LODCA and QTCM respectively, except for the parameters controlling the strength of the wind-evaporation feedback (see below). The reader is invited to refer to [16] and [91] for the values of the model's parameters. Two sensitivity experiments have been carried out which consist of increasing the coupling between SST and the ITV. The first experiment consists of increasing the strength of the wind-evaporation feedback in the model. In the QTCM model, the evaporation-wind feedback (also known as "wind-induced, surface heat exchange" or WISHE) is a mechanism at work that partially organizes the intraseasonal variability by reducing damping. In the evaporation-wind feedback theory, eastward propagation of convective regions is driven by anomalies in evaporation induced east of the convective regions by the rise of anomalous surface winds. In the simplest formulation, the anomalies of evaporation are induced by convectively driven low-level convergence, superimposed on top of mean easterlies, such that evaporation is enhanced east of the enhanced convection and suppressed west of the enhanced convection. Whereas it is not clear if such feedback is really at work to maintain the MJO in the observations, it has been proven to be at work in several general circulation models and experiments. In QTCM, along with the excitation by the extra-tropical storms, it is a main driving force for ITV (cf. [44] for details). This experiment is referred to as Newevap.

In the second experiment, the change in SST associated with heat flux anomalies is explicitly taken into account in the mixed-layer model of LODCA. Note that the standard version of LODCA only considered a damping term $(-\alpha T)$ that accounts for both dissipation processes and heat flux anomaly forcing. In the new experiments, named NewFlux, the damping term was reduced and the new value of $(1 / 150)$ days $^{-1}$ and the contribution of net heat flux anomalies to the rate of SST change is considered using a constant mixed layer depth of $50 \mathrm{~m}$ in the tropical Pacific $\left(20^{\circ} \mathrm{S}-20^{\circ} \mathrm{N}\right)$. Considering net heat flux, anomalies in the heat balance of the mixed-layer results in a stronger coupling between ITV and ocean wave dynamics. Net heat flux forcing is also considered outside the tropical Pacific, so that air-sea coupling also operates in the extra-tropics and the other tropical oceans through a slab-mixed layer. A seasonally varying mixed layer depth (derived from [12]) is used. It is beyond the scope of the present paper to study the effect of such coupling.

Since LODCA-QTCM was shown to simulate ITV characteristics that are in better agreement with the "observations" than the results obtained with forced simulation (i.e. with prescribed SST forcing) of QTCM (see the last section), only results of the coupled model are presented in 
this paper. The experiment Newevap with increased windevaporation feedback demonstrates the better agreement between the observations and model in simulating the ENSO/ITV relationships so that, for brevity, only results from this simulation are presented in the following. The differences between the two experiments (Newevap and Newflux) will be discussed in the last section.

\section{ITV characteristics}

The ITV is diagnosed from zonal wind at $850 \mathrm{hPa}$ (U850) and outgoing long wave radiation (OLR) because both fields are linked to both the MJO signal and the ENSO. OLR is a good proxy for tropical deep convection, as well as associated rainfalls. It is well known that convection and associated precipitation do not occur randomly in the equatorial belt but have been often organized by convectively coupled large-scale equatorial waves, such as MJO, Kelvin, ER, MRG, EIG, and WIG waves, e.g. [71, 72, WK99]. At the same time, the changes in deep convection distribution and intensity on the interannual scale are mostly associated with the ENSO variability in the equatorial Pacific. The zonal wind also exhibits a significant variability at intraseasonal time-scales with zonally propagating characteristics. Moreover the occurrence of westerly wind anomalies at 15-30 days, usually referred to as a westerly wind burst, were recognized as preceding the ENSO development in the eastern Pacific $[18,88]$.

Note that, in previous studies of ITV-ENSO teleconnections, the surface zonal wind is used $[29,52]$. However, our analysis revealed that the relationship between the MJO signal associated to zonal wind and SST anomalies in the equatorial eastern Pacific is stronger in the free atmosphere than near the surface. We suppose that MJO associated anomalies are more pronounced in the free atmosphere and the signal propagates toward the surface where it interacts with ocean dynamics. For these reasons, we chose to diagnose the ITV and its relation to ENSO from U850 in the subsequent analysis.

Figures 1 and 2 present the space-time spectra normalized above the background spectra for OLR and U850 wind respectively from the Reanalysis over 1977-2006 (left panel) and as simulated by LODCA-QTCM (experiment Newevap) (right panel) over a 30 -year period. The resulting contours can be thought of as levels of significance, with peaks in the individual spectra that are $20 \%$ above the background shown as shaded. Superimposed upon these plots are the dispersion curves for even (for antisymmetric component) and odd (for symmetric component) meridional mode number equatorial waves for various equivalent depths $(\mathrm{h}=8,12,25,50$ and $90 \mathrm{~m})$. The full space-time spectra are not presented here for brevity. However the full spectra for QTCM forced with observed SST are discussed in [26] and were shown to be similar to the ones obtained from LODCA-QTCM.

Signals of the Kelvin, ER, and WIG waves are obviously identified in the symmetric spectra for observed OLR (Fig. 1b), along with the MRG and EIG waves in the antisymmetric spectra (Fig. 1a). The MJO also appears as a prominent signal, especially in the symmetric spectra. As in WK99, all observed spectral peaks corresponding to shallow water modes best match an equivalent depth of around $25 \mathrm{~m}$ in the observational OLR data sets except for Kelvin waves in OLR symmetric components where the peak is shifted toward the deeper equivalent depth (around $50 \mathrm{~m}$ ) (Fig. 1b). WK99 explains such shallow equivalent depths (about an order of magnitude smaller than that for a free wave generated as the peak projection response to deep convective heating) as a result of the way convection is interacting with the dynamics.

The OLR spectra obtained from LODCA-QTCM exhibits some characteristics that are in good agreement with the observations. The model simulates signals of convectively coupled equatorial waves, with Kelvin and ER waves especially prominent (Fig. 1d). The MRG-EIG signal is almost lacking in LODCA-QTCM (Fig. 1c). The MRG signal could be distinguished in OLR spectra but with a different localization in the wavenumber axis as compared with observations (Fig. 1C). Two main discrepancies between observations and LODCA-QTCM are noted. The first one concerns the MJO: the peak corresponding to the MJO area is shifted toward the lower frequencies and the signal with respect to the background spectra has a lower amplitude. The second discrepancy concerns the Kelvin wave signal: for the lower frequencies, energy peaks are found away from the usual theoretical dispersion curves and towards the high zonal wavenumbers $(k=6)$. Also, the simulated signal appears in both the symmetric and antisymmetric spectra which suggests that the actual disturbances responsible for these spectral signals are asymmetric across the equator (rather than symmetric or antisymmetric) and corresponds to mid latitude waves instead of Kelvin waves. In order to verify that this spectral peak does correspond to disturbances associated with Kelvin waves, the spatial structure of these disturbances is estimated using the regression technique of [84]. As a first step, the OLR signal corresponding to the eastward wavenumbers 3 to 9 and the periods 2.5 to 40 days was estimated at each grid point and the time series associated to the average over the area of maximum variability is used to regress upon the total OLR fields. The obtained regression maps exhibit a pattern reminiscent of the Kelvin 

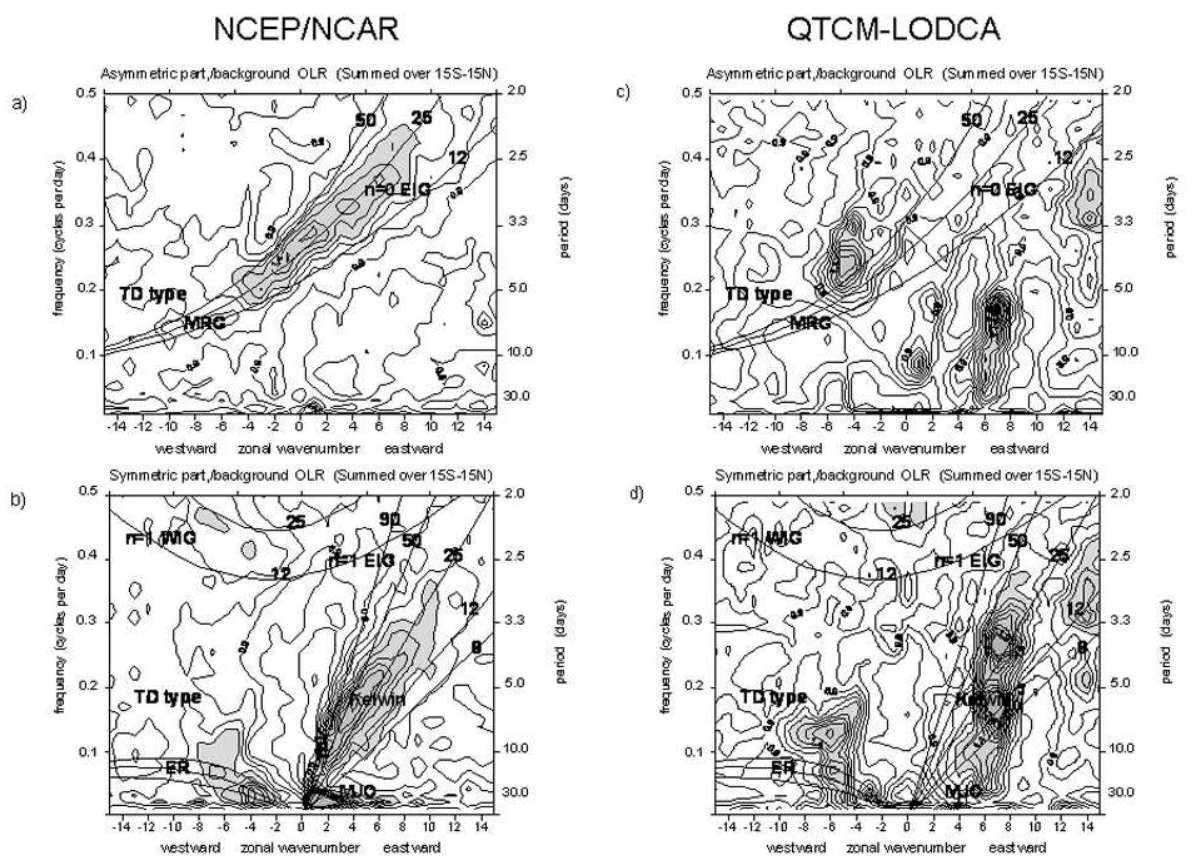

Figure 1. The antisymmetric OLR power divided by the background power $(\mathrm{a}, \mathrm{c})$. Contour interval is 0.1 and shading begins at a value of 1.2 for which the spectral signatures are statistically significant above the background at the $95 \%$ level (based on 500 d.o.f.). Superimposed are the dispersion curves of the even meridional mode-numbered equatorial waves for the equivalent depths $h$ of $812,25,50$ and $90 \mathrm{~m}$. (b, d) Same as in panel (a, c) except for the symmetric component of OLR and the corresponding odd meridional mode-numbered equatorial waves. Frequency spectral bandwidth is $1 / 48 \mathrm{cpd}$. Results obtained from NCEP/NCAR Reanalysis $(a, b)$ and from LODCA-QTCM (c, d).

structure, namely mostly symmetrical towards the equator and comparable to similar estimates from the Reanalysis data (not shown). This indicates that the model tends to simulate convective coupled Kelvin waves having slower phase speed (i.e. associated with smaller value of equivalent depth), which could be due to an overestimation of the coupling between atmospheric convection and oceanic equatorial Kelvin waves in the model. The disturbances corresponding to equatorial Rossby waves for the model also have a spectral peak that fit the dispersion curves associated to shallower equivalent depth than in the observations, which may reflect a systematic model bias.

Figure 2 is similar to Figure 1 but for the zonal wind at $850 \mathrm{hPa}$. For the Reanalysis, the regions of high energy match the theoretical dispersion curves of the equatorial Kelvin waves in a wide range of equivalent depths from 12 $\mathrm{m}$ up to $90 \mathrm{~m}$. The MJO is also found in both symmetric and antisymmetric components. The energetic westward moving symmetric synoptic-scale disturbances are found in the [3-8] days ${ }^{-1}$ frequency band, which do not correspond to any equatorial waves dispersion curves. Such waves in tropical convection have been well documented in previous studies, e.g. $[17,73]$ and are generally termed "tropical depression" (TD) disturbances occurring over a wide range of frequency and wavenumber. Another energy maximum is located at westward zonal wavenumber 1 that corresponds to the westward moving long planetary zonal wave.

The discrepancy between model and observations is comparable to OLR (Fig. 1), namely a weaker MJO and a too energetic Kelvin wave in the vicinity of the zonal wave number 6 at low frequency. The signal associated to the MJO stands at 1.5 times (or $50 \%$ ) above the background for the model, whereas, for the observations, it stands 4.5 times above the background in the [20-40] days $^{-1}$ frequency band for zonal wave number 1 to 3 (with the background of the same order for the model and observations). The spatial patterns associated with the unrealistic model spectral maximum around eastward wave number 6 were analyzed using the method described above. Their maximum amplitude in the extra-tropical regions and their asymmetric structure suggests that the model Kelvin 

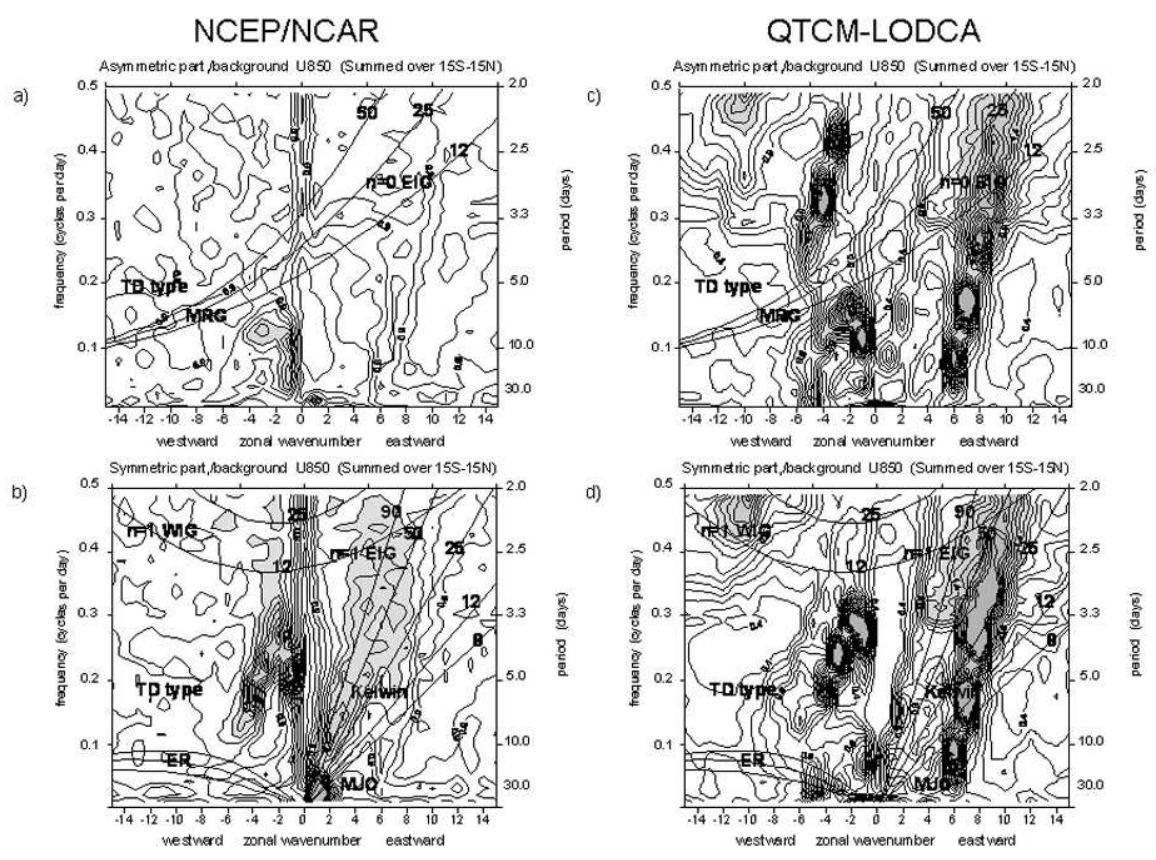

Figure 2. Same as Fig. 1 but for U850

waves have a strong association with the extratropical waves. Noteworthy, a similar asymmetric pattern emerges for the Reanalysis when the zonal wind is regressed onto the filtered data averaged over $\left(120^{\circ} \mathrm{E}-180^{\circ} \mathrm{E}, 0^{\circ}-5 \mathrm{~N}\right)$, with, however, a maximum amplitude closer to the equator. The main deficiency of the model is in fact related to the simulation of the low frequency Kelvin wave. The regression map of U850 onto the filtered (4-9 eastward wavenumber; 2.5-40 days) data averaged over the equatorial western Pacific $\left(100^{\circ} \mathrm{E}-140^{\circ} \mathrm{E} ; 5^{\circ} \mathrm{S}-5^{\circ} \mathrm{N}\right)$ indicates that the model tends to simulate disturbances too much to the North compared to the observations (not shown). However, the expression of these disturbances along the equator is consistent with the Kelvin wave pattern since the wavelength and the phase speed of these disturbances is comparable to that of the observed Kelvin wave (cf. Fig. 7 in [26]). The high frequency Kelvin waves (period less than 3 days) are realistically simulated by the model (not shown), as well as the TD-type disturbances, although their spectral peak has a slightly different space-time localization and higher energy than in the observations.

Despite these biases, the LODCA-QTCM skill in simulating the ITV characteristics is comparable to most Coupled General Circulation Models (cf. [45] for a comparison of the spectra with the ones of the IPCC models).

\section{ENSO/ITV seasonal relationship}

It has been shown recently that the relationship between ENSO and MJO activity exhibits a strong seasonal dependence $[29,52]$. To analyze the ENSO/ITV interaction in relation to the seasonal cycle, a method similar to the one proposed by Hendon et al. [29] is applied. Whereas Hendon et al. [29] focuses on the MJO signal, here we extend his approach to the other component of the ITV (see section 2).

\subsection{Model-data comparison}

The lag-correlation between January SST in the Nino 3.4 region and the equatorially averaged wave amplitude for OLR (Fig. 3) and U850 (Fig. 5) is presented as a function of longitude. The lag-correlation of the Nino 3.4 SST index (smoothed with a 3-month running mean) with respect to the indices associated with each wave type (see Table 1 ) is also presented as a function of calendar month (start month) for OLR (Fig. 4) and U850 (Fig. 6). The upper (bottom) panel displays the results for the NCEP/NCAR Reanalysis (LODCA-QTCM). Correlation higher than 0.34 is significant at $95 \%$ significance level assuming Gaussian 
statistics with 30 independent samples. In Figs 3-9, the areas with correlation higher (less) than $0.30(-0.30)$ are shaded.

\section{MJO signal}

We first focus on the MJO disturbances, for which two interesting features can be underlined:

1. At zero time lag, the dipole correlation structure appears in the MJO-filtered OLR of the Reanalysis. It consists of enhanced MJO convection in the central and eastern Pacific (positive correlation) and a reduction of $\mathrm{MJO}$ associated convection over the Indian Ocean and Western Pacific (negative correlation) (Fig. 3a). This is in good accordance with the well-known intensification of convection over the warm SST region and decrease of the deep convection over Australia and Indonesia, leading to the dry conditions (fires) in these regions during the mature phase of El Niño [78]. Noteworthy, the coupled model accurately simulates these relationships with a similar longitudinal location and amplitude of the positive and negative correlation zones to the Reanalysis, with however slightly lower negative correlation in the model. The enhancement of the $\mathrm{MJO}$ in the eastern Pacific during the mature phase of El Niño (Jan. 0) is less pronounced for low troposphere zonal winds than for OLR in the Reanalysis (compare Fig. 3a with Fig. 5a). The decrease of MJO-associated winds over the Western Pacific and Indian oceans, in opposition, is more marked. The LODCA-QTCM tends to overestimate the ENSO associated enhancement of MJO-filtered U850 in the central Pacific but does capture the equatorial dipole structure of correlation distribution (Fig. 5a, d).

2. The most important signal in MJO occurs 6-8 months before the maximum of SST anomalies (in May-June, preceding El Niño). The wide area of positive correlation could be depicted in the western Pacific (in the vicinity of $80^{\circ}-140^{\circ} \mathrm{E}$ ) both for the observed MJO-filtered OLR and U850 (Figs 3a, and 5a). Thus enhanced MJO amplitude in the Western Pacific leads the maximum of equatorial Pacific warming by 6 to 8 months. In the case of low troposphere wind, this area of enhanced MJO amplitude extends towards the eastern Pacific, which implies the eastward propagation of $\mathrm{MJO}$ associated wind anomalies across the Pacific in the late spring-summer, preceding El Niño (Fig. 5a). Note that similar features were found by Hendon et al. [29] and McPhaden et al. [52] from the same observations with a somewhat different timing. In particular, they found that maximum lag correlation is observed one month earlier (April-May).

Interestingly, the coupled model is able to simulate similar phase relationships. However the model maximum correlation has lower amplitude, is shifted eastward for the MJO-filtered OLR and appears later (in June-July) for MJO-filtered U850 as compared to the Reanalysis.

We now investigate the phase relationship between the MJO index (WPacMJO ${ }_{O L R}$ ) and the Nino 3.4 SST index from June to December, which corresponds to the period of eastward displacement of the strong convection associated with the warm SST over the equatorial Pacific. Most attention has to be paid to the positive lag correlation between $\mathrm{WPacMJO}_{O L R}$ and SST Nino 3.4, which corresponds to MJO leading SST (Fig. 4a). Hendon et al. [29] pointed out the strong seasonal dependence of this relationship: when all months are considered together, the maximum lagged correlation of the Nino 3.4 SST index with respect to Western Pacific MJO is 0.4 and 0.3 for 3 and 8 months lag respectively (SST Nino 3.4 lagging) for the observations. However, the correlation between the $\mathrm{MJO}$ in the western Pacific in the spring-summer and the Nino 3.4 SST index in the subsequent December is much larger (peaking to 0.6). Similar strong seasonal dependence between WPacMJO $O L R$ and SST Nino 3.4 is encountered here. Significant positive correlation appears at lag 11 months and persists up to the time lag of 1 month, the correlation increasing at small lags (Fig. 4a). It implies that increase of MJO-filtered OLR amplitude in the western Pacific in summer is highly correlated (correlation higher than 0.5 ) with the Nino 3.4 SST index in the following autumn-winter. For low troposphere zonal wind, such a correlation pattern is less pronounced and the significant correlation occurs one month earlier but the overall behavior is similar (Fig. 6a). The intensification of MJO-filtered U850 at the beginning of the summer correlates with the Nino 3.4 SST index 1-11 months later (wind leads). The wide interval of time-lags is not surprising as the SST anomaly associated with El Niño is characterized by a strong persistence from the summer to the next spring. The high correlation for the wind is more extended to the negative time lag reflecting the Western Pacific wind's dependence on the previous ocean state (Fig. 6a). Interestingly, LODCA-QTCM also simulates a strong seasonal dependence of the lag relationship between MJO amplitude in the Western Pacific and the Nino 3.4 SST index (Figs $4 \mathrm{e}$ and 6e). However the area of high correlation is shifted towards the second half of the years compared to the Reanalysis, thus MJO enhancement preceding SST anomalies takes place with too much delay in the model. 

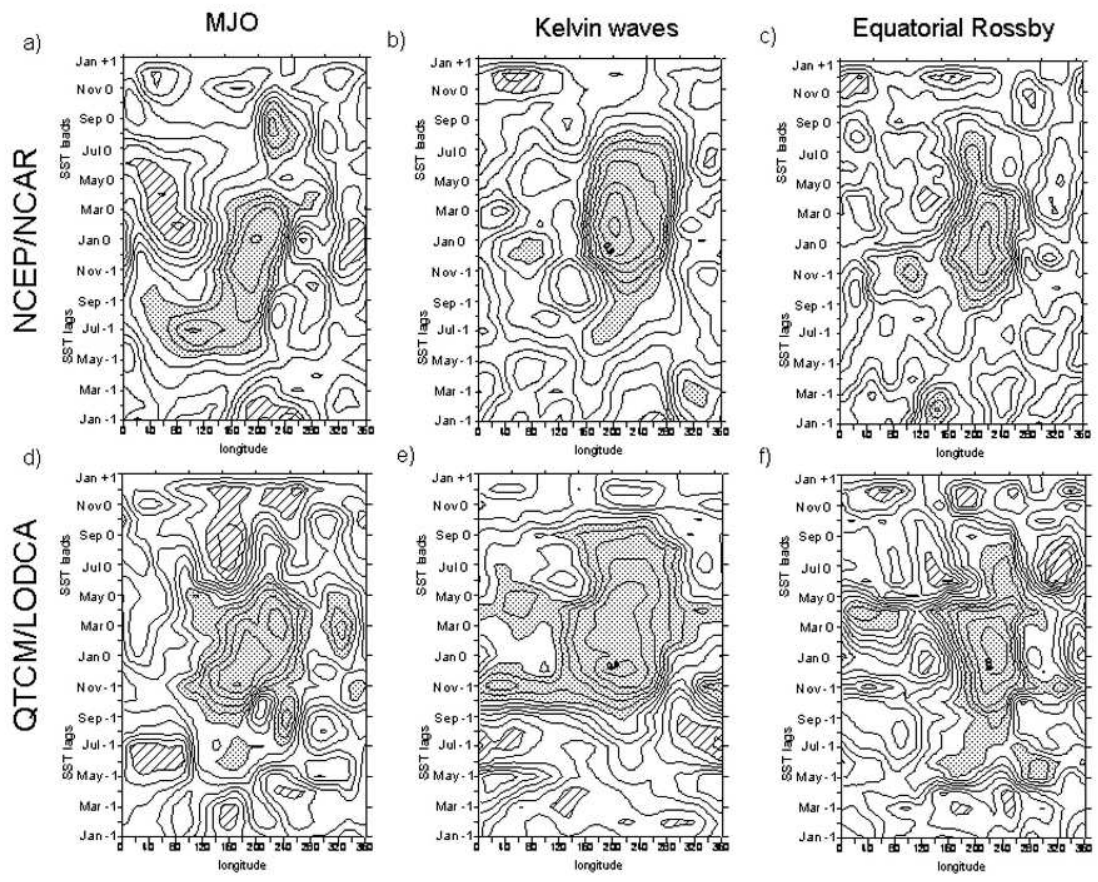

Figure 3. Lagged correlation of equatorially averaged OLR with SST Nino $3.4(\operatorname{Jan}(0))$. MJO-filtered - left column, Kelvin wave-filtered - central column, N1ER-filtered - right column. Results for NCEP/NCAR - upper panel, LODCA-QTCM - bottom panel. The period is 1977-2006 for the Reanalysis and 108-137 years for the model. Contour interval is 0.1 . Correlation values higher (smaller) than $0.3(-0.3)$ are shaded.

Another unrealistic feature can be evidenced from the comparison of Figures $6 a$ and $6 e$, namely the persistent positive correlation between the Nino 3.4 SST index and the MJO index in May, present in the model and not in the Reanalysis. The reasons for such discrepancies between model and observations are unclear. It could be due to the simplified physics of the ocean model which may not grasp properly the evolution of the coupling between the oceanic Kelvin wave and the atmospheric convection over the course of ENSO [59], resulting in a different phasing between SST and the MJO than observed at some ENSO stages. It is beyond the scope of the present paper to investigate such issue.

\section{Convective equatorial Kelvin and Rossby waves}

Whereas, the relationship between MJO and ENSO has been widely considered [29, 52, 89], the role of other equatorial convective coupled waves in the mechanism of ENSO still remains unclear. Here, using a similar approach as for the MJO signal, we investigate the seasonal dependence of ENSO and the variance of atmospheric Kelvin and Rossby waves.
Figure 3 presents the correlation between recomposed waves and Nino 3.4 SST index in January as a function of longitude. Not surprisingly, a strong simultaneous correlation between OLR equatorial Kelvin waves in the central and eastern Pacific (in the vicinity $160^{\circ} \mathrm{E}-80^{\circ} \mathrm{W}$ ) and SST anomalies at the peak of El Niño (Fig. 3b) can be evidenced, which is the consequence of the intensification of deep convection in these regions associated with the eastward displacement of warm pool waters. The maximum correlation occurs when OLR lags SST by one month, which reflects some inertia of the atmosphere reaction to the ocean forcing. The model behavior looks very similar (Fig. 3e). Furthermore, the lag relationship may be depicted in the OLR field. The Kelvin wave activity in the central Pacific from June to December before the peak phase of El Niño is significantly related to the January Nino 3.4 SST index (Jan 0) while the intensification of the Kelvin wave over the Indian Ocean takes place in December (-1) (Fig. 3b). Both correlation patterns are captured by the model, although the first one has lower values for the model than for the Reanalysis and the second one has larger values (Fig. 3e)

For the observed U850 Kelvin wave, we find that the 

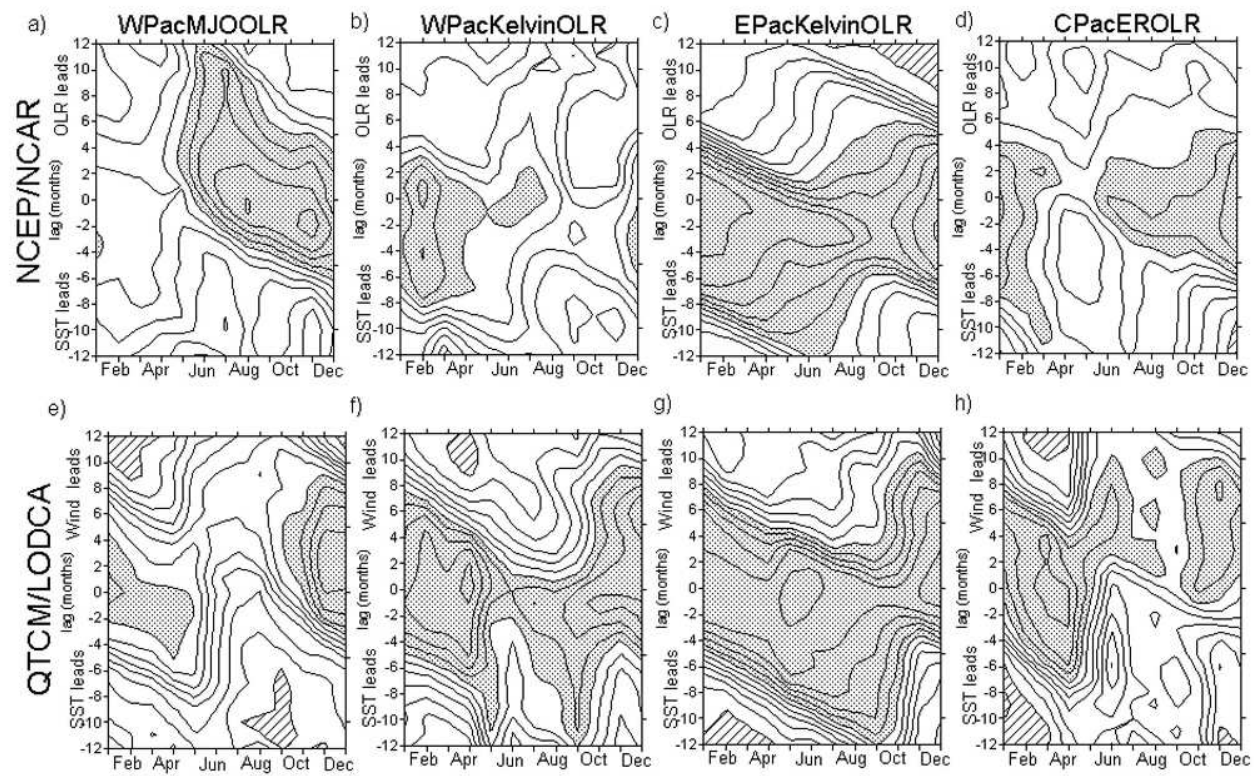

h)

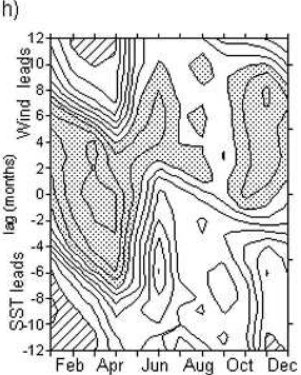

Figure 4. Monthly lagged correlation of SST Niño 3.4 as a function of start month with respect to a,e) WPacMJO $O L R$ b,f) WPacKelvin $O L R$ c,g)

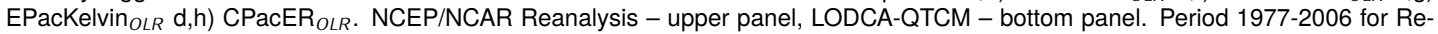
analysis and 108-137 years of model run. Contour interval is 0.1 . Correlation values higher (smaller) than $0.3(-0.3)$ are shaded.

seasonal dependence consists mostly of an atmospheric response to the ocean forcing since positive correlations are found at year +1 , i.e., SST leading the atmosphere (Fig. 5b). This is also true for the model (Fig. 5e). At high-frequency, the oceanic equatorial Kelvin wave in the equatorial Pacific has a relatively short zonal scale [15] and may dissipate rapidly at the surface through vertical propagation, so it is not likely that coupling between convective Kelvin wave and ocean Kelvin wave explains such a correlation pattern. Rather, these convective waves are most often triggered by interaction of extratropical waves with the equatorial waveguide [69]. The stronger expression of these Kelvin waves over the Pacific basin during $\mathrm{El} \mathrm{Niño} \mathrm{is} \mathrm{therefore} \mathrm{likely} \mathrm{associated} \mathrm{with} \mathrm{increased} \mathrm{am-}$ plitude in convection coupled to the waves because of the warmer SST background state.

The comparison between model and observations for the relationship between the Kelvin wave activity index (WPacKelvin $_{O L R}$ and WPacKelvin ${ }_{U 850}$ ) and the Nino 3.4 SST index (Figs $4 b, f$ and $6 b, f$ ) reveals that the model tends to simulate a too strong Kelvin wave response in the western Pacific although the timing is comparable in both products. The fact that the model overestimates the atmosphere response to the ocean forcing was previously mentioned by [19]. Note however that the model overestimates the Kelvin wave activity only in the Western Pacific. In the eastern Pacific, the Kelvin wave intensification lagging SST maximum, is observed in the Reanalysis both for OLR (Fig. 4c) and U850 (Fig. 6c). This feature is simulated correctly by the coupled model for OLR (Figs 4g). A worse agreement between the model and reanalysis for U850 may be due to the incorrect simulation of low frequency component (i.e. [5-30] days period band) of the convective equatorial Kelvin waves in the model (Fig. 6f, g).

The results for the equatorial Rossby wave response are presented in the Figures $3 c, f$ and $5 c, f$ (correlation with the Nino 3.4 SST index in January) and the Figures $4 d, h$ and $6 \mathrm{~d}, \mathrm{~h}$ (lag relationship with the Nino 3.4 SST index as a function of calendar month). The most outstanding result is the strong leading relationship between equatorial Rossby waves and the subsequent El Niño. Our analysis demonstrates that equatorial Rossby waves play a crucial role in the El Niño initiation mechanism like the MJO. The area of high correlation for the U850 ER (Fig. 5c, cor $>0.4$ ) appears 7 months before the El Niño 
a)

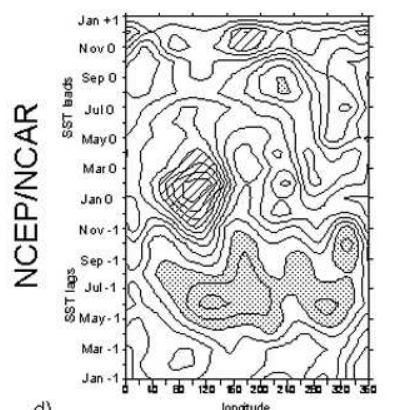

d)

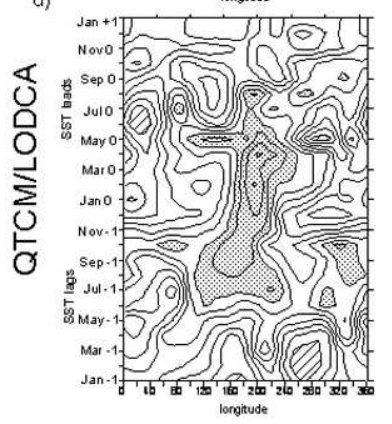

c)

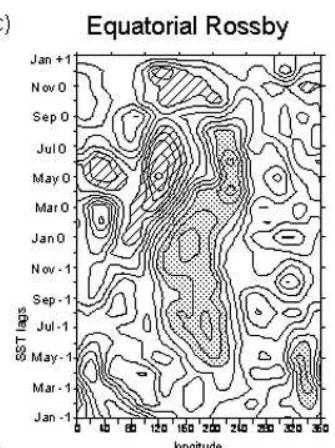

f)
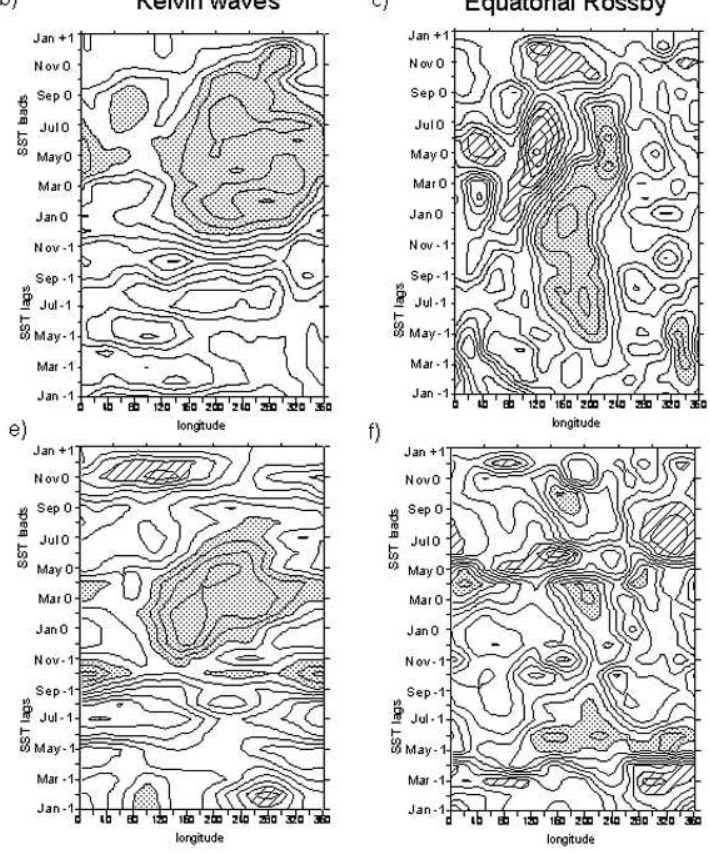

Figure 5. Same as Fig. 3 but for U850.

peak phase in the vicinity of the dateline with the maximum correlation in July. In the light of these results, it is suggested that the intensification of equatorial Rossby waves in the central equatorial Pacific in summer is followed by the positive SST anomalies in the eastern $\mathrm{Pa}-$ cific in winter. Figure 7a presents the lag correlation between SST anomalies along the equator and the ER activity index $\left(\mathrm{CPacER}_{U 850}\right)$ taken in July. It indicates that the Rossby wave intensification in the central Pacific in July is associated with eastward propagating SST anomalies that reach the South American coast 6 months later, namely in January. Concomitantly, the $\mathrm{CPacER}_{U 850}$ index in July is highly correlated to the low troposphere winds along the equator and the lag correlation pattern between both exhibits similar eastward propagating characteristics (Fig. 7b). The westerly winds that are highly conducive to El Niño conditions are associated not only with the MJO enhancement but also with the intensification of Rossby waves. Hendon et al. [29] proposed that MJO activity in the western Pacific promotes sustained westerly surface winds, which themselves promote and are promoted by warm SST and atmospheric convection on the eastern edge of the warm pool. They argued that this feedback is most pronounced in spring, when convection and westerlies are most sensitive to SST anomalies on the edge of the warm pool. For equatorial Rossby waves, it is shown here that the strongest covariability takes place during the summer season and is located in the central Pacific. We thus hypothesize the following mechanism of interaction between SST and equatorial Rossby waves: El Niño typically begins with a rapid expansion of the warm pool into the eastern Pacific approximately beginning in April, which coincides with the seasonal redevelopment of the cold tongue. This initial eastward expansion of the warm pool is accompanied by westerly anomalies in the western Pacific that are evident as far back as the preceding winter, e.g., [10]. Thus, the wind anomalies associated with enhanced $\mathrm{MJO}$ activity would project strongly onto these westerlies that accompany the development of El Niño in spring. Furthermore, a positive feedback between the MJO and El Niño development is implied in spring. Anomalously warm SST on the eastern edge of the warm pool in March and April, which typically precedes the development of El Niño, promotes enhanced MJO in June, which then promotes enhanced surface westerlies in the western Pacific [29]. The careful inspection of Figure 7 reveals that the $\mathrm{CPacER}_{U 850}$ index in July is correlated with the equatorial SST and low troposphere winds in the Western Pacific 2 to 4 months earlier. This indicates that the intensification of Rossby wave activity in 


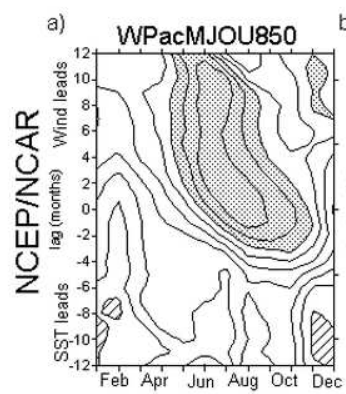

e)

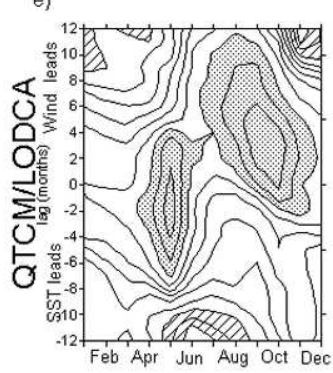

b) WPacKelvinU850
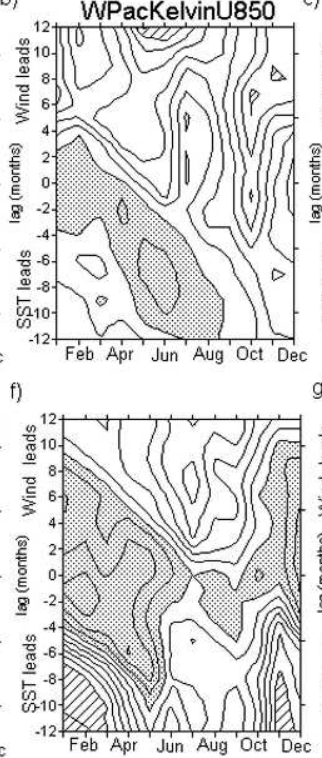

EPacKelvinU850

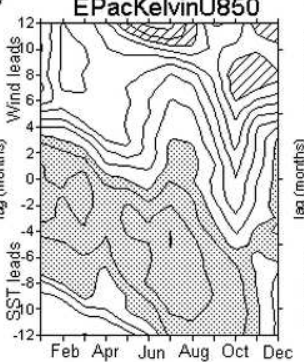

g)

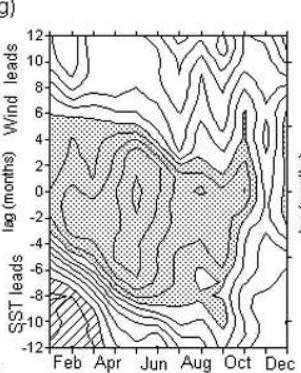

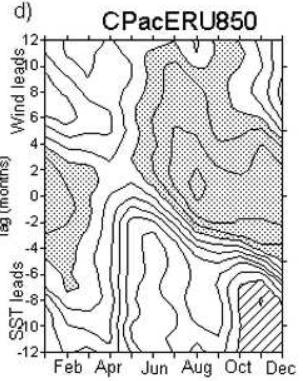

h)

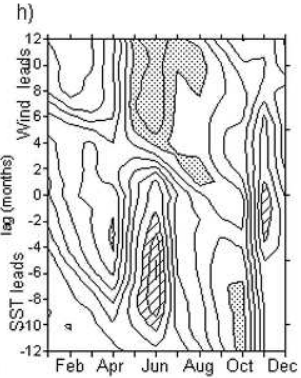

Figure 6. Same as Fig. 4 but for U850.

the central Pacific is related to the preceding intensification of the MJO in the Western Pacific. We then argue that the westerlies associated with the MJO enhancement expands to the east in association with the eastward displacement of the eastern edge of the warm pool, which in turn is promoted by westerly winds and eastward advection of east-west temperature gradient. When the area of anomalous westerlies reaches the central Pacific, the equatorial Rossby waves contribute to the intensification of westerlies and enhance the positive feedback. This mechanism implies the positive feedback between ENSO and equatorial Rossby waves. Matthews and $\mathrm{Ki}-$ ladis [50] demonstrated the associations between extratropical Rossby waves and equatorial Rossby waves. Extratropical Rossby waves may propagate into the tropics when continuous regions of westerly wind extend between the two regions. The state of ENSO and the seasonal cycle might favor the locations of these regions of westerly winds, thus these factors determine the most likely locations for equatorial Rossby wave formation. Consequently some association between equatorial Rossby waves and ENSO may occur even if the equatorial Rossby waves do not influence ENSO at all (i.e., the association might not necessarily imply causality. ENSO might simply modulate the regions in which the equatorial Rossby waves occur). On the other hand, a closed feedback loop might occur if ENSO modulates the equatorial Rossby waves, which in turn might influence ENSO through their asso- ciated stress on the ocean surface and their modulation of atmospheric convection.

Such mechanisms will have to be tested from specific model experiments or based on case studies. It is beyond the scope of the present study. At this stage, it is interesting to note that, consistently with results by Shinoda et al. [66], intraseasonal variations in the east Pacific wind anomalies influence the amplitude and propagation speeds of Kelvin waves triggered farther west. If these atmospheric waves can influence the Kelvin waves, then they might influence the impact of the Kelvin waves on SST. This is the necessary condition for the existence of the feedback loop associated with the equatorial Rossby wave proposed above.

It is worth pointing out the results of [93] that suggest another mechanism of the interaction between MJO and ENSO. In particular, they propose that the connection between the two operates through the excitation of intraseasonal oceanic Kelvin waves that propagate into the eastern Pacific where they interact with El Niño. Consistent with their theory, it is suggested here that the atmospheric equatorial Rossby waves may influence the oceanic Kelvin wave in the central Pacific through the generation of anomalous westerly winds. It is beyond the scope of this study to test such mechanism of wave-wave interaction.

LODCA-QTCM simulates similar correlation patterns as 
a)

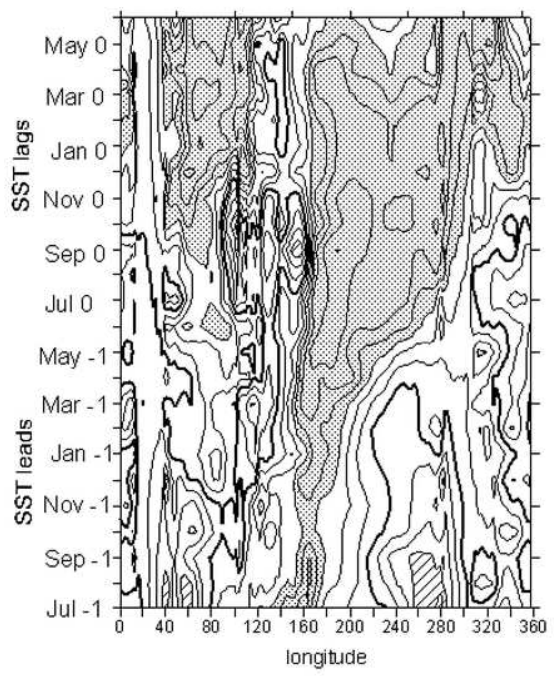

b)

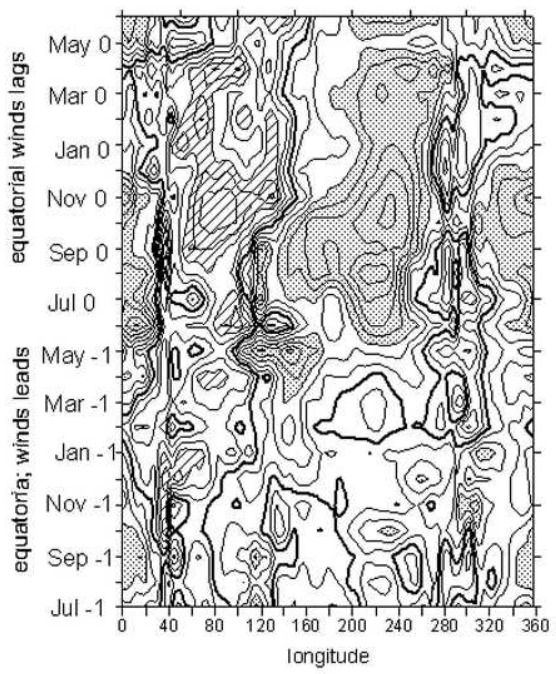

Figure 7. a) Lagged correlation between the equatorial SST anomalies and CPacER 4850 in July (Jul 0) b) Lagged correlation between U850 anomalies along the equator and $\mathrm{CPacER}_{U 850}$ in July (Jul 0).

the observations for the relationship between ER-filtered U850 in summer and Nino 3.4 SST in January, with, however, the maximum located one month earlier - in June (compare Figs 5c, f). The main deficiency of the model is its inability to simulate the spreading of the positive correlation in the central and eastern Pacific for positive lags (i.e. SST leading) across the whole Pacific. Note that this is more pronounced for $U 850$ than for OLR (Figs 3c, f).

Analyzing the lag relationships between $\mathrm{CPacER}_{U 850}$ and the equatorial Pacific SST, we can note the strongest simultaneous correlation beginning in August and persisting up to February (Fig. 6d). This can be explained in terms of a linear response (Gill-type, [19]) of the atmosphere to a heat source, which results in Rossby wave generation to the west of the heat anomalies located along the equator. The role of ER waves in ENSO initiation is evidenced by the high correlation observed at positive time lags, which implies the interaction between ER in the central Pacific and following anomalies of SST in the Nino 3.4 box (Fig. 6d). The model exhibits a similar pattern although simultaneous correlation is not present (Fig. 6h).

The lag relationships between central Pacific Rossby wave-filtered OLR and subsequent equatorial SST anomalies are not obvious in the Reanalysis (Fig. 4d). The model tends to overestimate this interaction (Fig. 4h). However, the model captures the simultaneous correlation between the OLR Rossby wave intensity in the central
Pacific and the SST anomalies at the peak of El Niño (Fig. 3f, 4d). As the maximum SST anomalies in January are located in the eastern Pacific and the maximum of correlation - near the date line, we can suppose that this traduces the linear response of the atmosphere to the heat source described above. The model simulates this mechanism realistically.

\subsection{Decadal modulation}

It is known that the intensity of ENSO exhibits significant decadal modulation $[2,3,11,75]$, In particular, the 1976/77 climate shift is associated with significant changes in ENSO statistics (frequency, amplitude, propagating characteristics and asymmetry) $[1,2]$. Recent studies also emphasized two type of El Niños: the canonical El Niño as described in [25, 57] which is characterized by SST anomalies located in the eastern Pacific and the so-called central Pacific El Niño (also termed the dateline El Niño, El Niño Modoki or warm pool El Niño) with anomalous SST shifted toward the dateline and cooler water located to the east and to the west $[4,33,37,38]$. This latter type of El Niño differs significantly in both the location of maximum SST anomalies and tropical to mid-latitude teleconnections, and consequently might be associated with a different seasonal dependence of the ITV/ENSO relationship. 

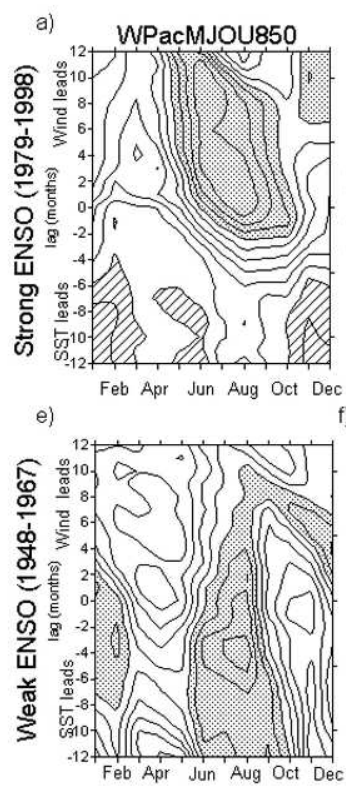
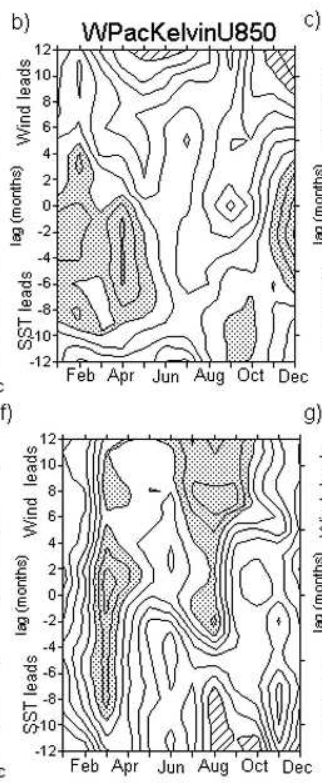

g)
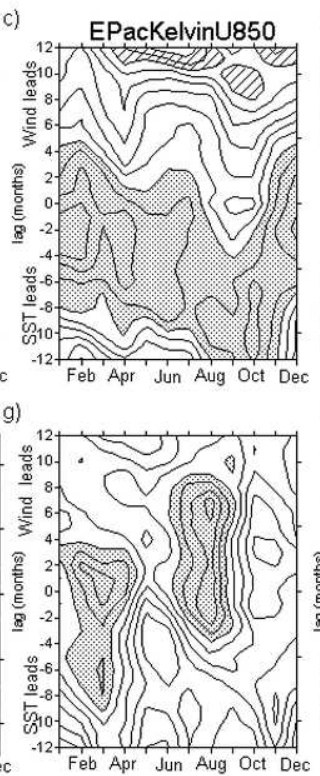

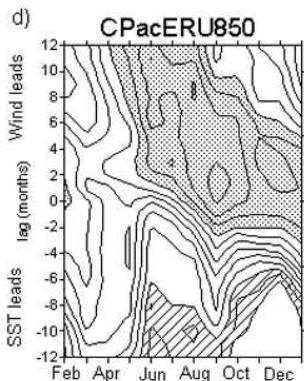

h)

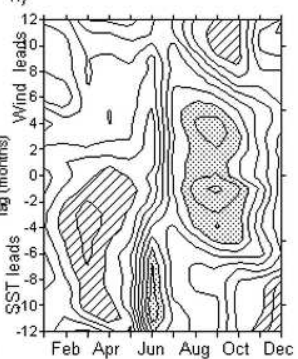

Figure 8. Monthly lagged correlation of SST Nino 3.4 as a function of start month with respect to a,e)WPacMJO ${ }_{U 850}$ b,f)WPacKelwin ${ }_{U 850} \mathrm{c}, \mathrm{g}$ ) EPacKelwin $_{\cup 850}$ d,h) CPacNIER 4850 . NCEP/NCAR Reanalysis. Period of strong ENSO amplitude (1979-1998) upper panel, the period of relatively weak ENSO amplitude (1948-1967) - bottom pannel. Contour interval is 0.1 . Correlation values higher (smaller) than 0.3 $(-0.3)$ are shaded

Since the seasonal dependence between ITV and ENSO as evidenced in this paper is a fundamental characteristic of the tropical Pacific system, one may wonder if it is sensitive to the characteristics of ENSO itself, which includes its low frequency modulation. Comparison of two periods identified as "strong ENSO activity" (1979-1998) and "low ENSO activity" (1948-1967), corresponding to the transition of the 1976/77 climate shift, allows testing of the sensitivity of the ITV/ENSO relationship to changes in mean state. Figure 8 presents the lag relationship between the Nino 3.4 SST index and the wave indices for the two periods. It can be compared to the Figures $6 a, b, c$ which are for the "full" period. Similarly, Figure 9 is similar to Figure 5 except for the periods before and after the 1976/77 climate shifts. Interestingly, a drastic change in the ENSO/ITV relationship is observed between the two periods. First of all, during the period of "strong ENSO" activity, the MJO activity precedes the SST rise in the eastern Pacific by 2-10 months, whereas during the period of "weak ENSO" activity, large MJO variance takes place in the Western Pacific 5 months after the peak of El Niño and the MJO does not lead El Niño. When the MJO activity is correlated with SST Nino 3.4 in January (Fig. 9a, d), the region of high correlation for the period of weak ENSO is shifted to the eastern Pacific as compared the period of strong ENSO activity and the intensification of the MJO takes place in August instead of May.

Comparable differences can be evidenced for the convective equatorial coupled waves. In particular, the growth of Kelvin wave intensity over the Western Pacific takes place after the maximum positive SST anomalies over the period of strong ENSO activity while over the period 194867 (weak ENSO activity) another Kelvin wave signal appears 5-8 months before the SST maximum (Figs 8b, f). Similar behavior is evidenced for EPacKelvin 4850 , with a clear response to SST anomalies over the period of strong ENSO whereas during the period of weak ENSO activity (Fig. 8c, g), the Kelvin wave variability is ahead of the El Niño peak. Over 1979-98, the Kelvin waves appear over the equatorial Pacific simultaneously with the ENSO peak and spread to the east during the following spring-early summer (Fig. 9b). Over 1948-67, two areas of high correlation are observed: one is located in the spring following the El Niño peak and the next, during the preceding summer (Fig. 9e).

Over the period 1979-98, CPacER $\mathrm{U}_{450}$ exhibits persistent correlation with Nino 3.4 SST during 12 months prior to El Niño. The period of weak ENSO activity is characterized by two weak signals in equatorial Rossby waves in the central Pacific preceding and following SST extremes (Figs 8d, h). When the correlation between equatorially 

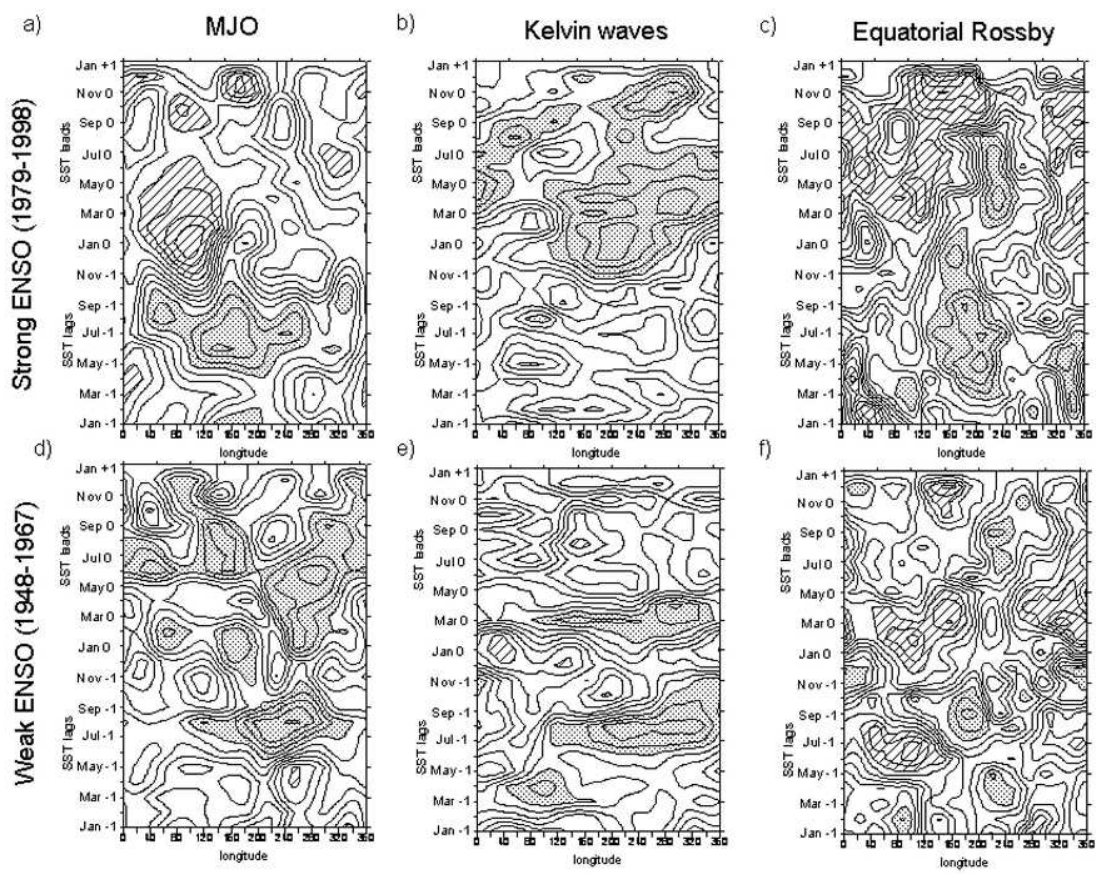

Figure 9. Same as Figure 5 for the period of strong ENSO amplitude (1979-1998) and the period of relatively weak ENSO amplitude (1948-1967).

averaged Rossby wave and Nino 3.4 SST in January is considered, the intensification of Rossby waves emerge, which starts in March of Year -1 and lasts until the peak of ENSO in January during the period of strong ENSO activity. During the weak ENSO period this signal is less pronounced (Fig. 9f).

In the light of this analysis, we can conclude that the causative relation between ENSO and ITV patterns are strongly dependent on the period under investigation. Namely the intensification of MJO and equatorial Rossby waves in the western-central Pacific preceding El Niño are typical of the period of strong El Niño amplitude. The period of weak ENSO activity is characterized by a completely different ITV/ENSO relationship in the tropical troposphere.

In order to investigate further the low frequency modulation of the ITV/ENSO relationship, the long-term LODCAQTCM simulation is used (experiment Newevap, see section 3). Note that the analysis of the model outputs may also test the null hypothesis that would consider that the change in the ITW/ENSO relationship evidenced in the observations result from the increases in observational samplings due to satellite-derived winds assimilated in the NCEP- NCAR reanalysis.
LODCA-QTCM exhibits a realistic ENSO amplitude modulation [14], which allows selecting periods of strong and weak ENSO activity. The so-called N3VAR index (cf [9]) is used to quantify the ENSO modulation. It is calculated from the integral between 2 and 7 years of the wavelet power coefficient of the Nino 3 SST anomalies [74]. To compare with the observations, chunks of 20 years were used (143-162 model years for "weak ENSO" and 7998 model years for "strong ENSO"). 20-year periods (to be consistent with observation) when the N3VAR index is predominantly lower (larger) than its standard deviation over the 250 years are periods of "weak ENSO" ("strong ENSO").

Figure 10 is similar to Figure 9 except for the model and just for MJO and Rossby waves. These two types of ITV disturbances were chosen as they demonstrate the strongest leading relationships with the subsequent El Niño. It is evidenced that the model also exhibits the marked decadal modulation of ENSO/ITV relationships. The teleconnection patterns for the wave's intensity preceding and following the peak of El Niño differ both in space and time during the period of strong and poor ENSO activity. Thus we may suppose that causative relation between MJO and equatorial Rossby waves and SST in the model depends on the mean state of the system. 
a)

c)

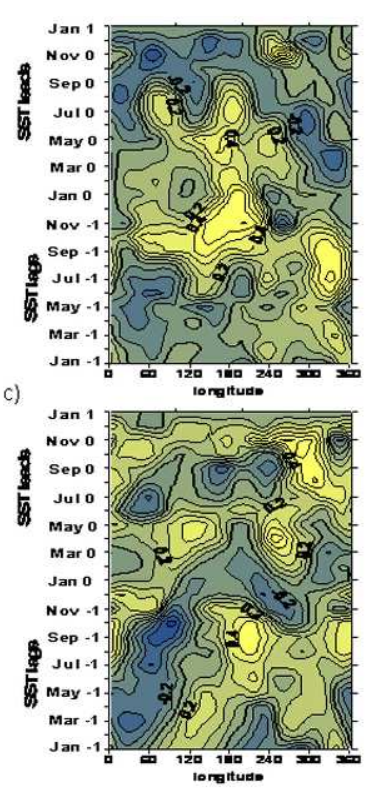

b)

d)

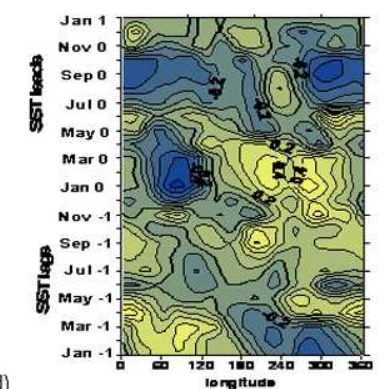

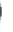

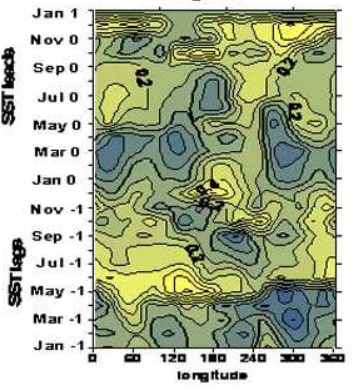

Figure 10. Same as Figure 8 for LODCA-QTCM. The period of strong ENSO amplitude (78-97 model years) - upper panel, period of relatively weak ENSO amplitude (143-162 model years) -bottom panel. MJO filtered data (a, c), ER-filtered data (b, d).

\section{Conclusion}

Double space-time Fourier analysis was applied in order to identify and document intraseasonal tropical variability patterns in the tropical troposphere following the method of WK99. Madden-Julian oscillations as well as convectively coupled equatorial Kelvin and Rossby waves were investigated based on the NCEP/NCAR Reanalysis data for the 1977-2006 period and the outputs of a hybrid ocean-atmosphere model that consists of a simple linear ocean model of the tropical Pacific coupled with an intermediate complexity atmospheric model.

The experiment Newevap (with increased windevaporation feedback) was chosen as it is the one that exhibits the strongest $\mathrm{MJO} / \mathrm{ENSO}$ relationships comparable to observations and as compared with forced QTCM model and experiments Newflux of the coupled LODCA-QTCM model (Fig. 11).

It was shown that LODCA-QTCM is capable of simulating the convectively coupled equatorial waves in OLR and U850 fields with skills comparable to other CGCMs (see [45]). Note that the earlier versions of many GCM models almost did not have the signal corresponding to these waves [83]. Since it is thought that the interplay between convectively coupled waves is important to the low frequency variability of the tropical atmosphere, e.g. $[37,47,48]$, the existence of a wide variety of observed equatorial waves in LODCA-QTCM opens the possibility to use such intermediate complexity models to study the mechanisms of the coupling between the intraseasonal oceanic Kelvin waves and atmospheric convection (e.g., [58]). In particular, Roundy and Kravitz [59] show that these convective waves evolve differently with their associated weather patterns during different phases of ENSO whether they are timed with the intraseasonal oceanic equatorial Kelvin wave or not (see also [66]).

Further the seasonal relationship between ITV and ENSO relationships is estimated in both products. A strong seasonal dependence is found for all three types of ITV disturbances. The fact that MJO activity in spring-summer is associated with the strength of a subsequent El Niño is confirmed in agreement with recent other investigations $[29,51]$. A new finding is the similar behavior of the equatorial Rossby waves with respect to ENSO. In particular, the lagged correlation between ER waves and the Nino 3.4 SST index is of the same order as for the MJO. On the other hand, the convectively coupled Kelvin waves lag the 
a)

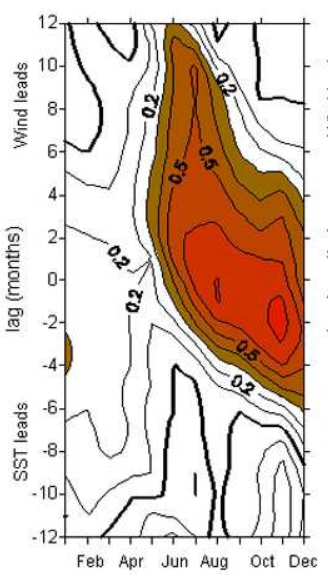

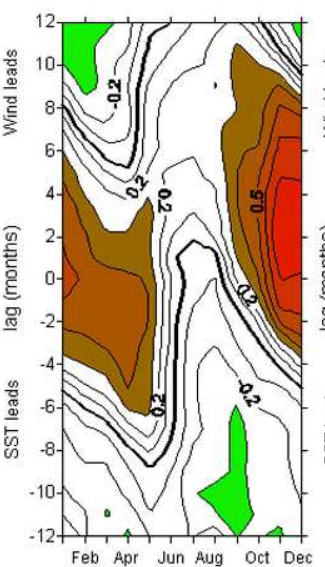

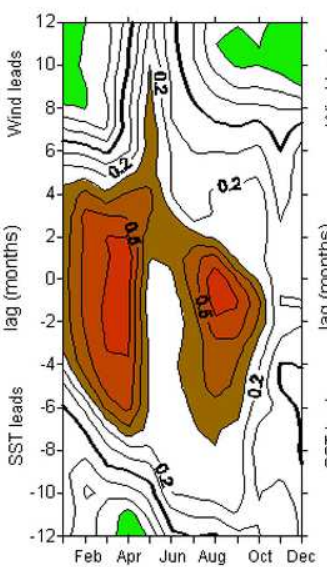

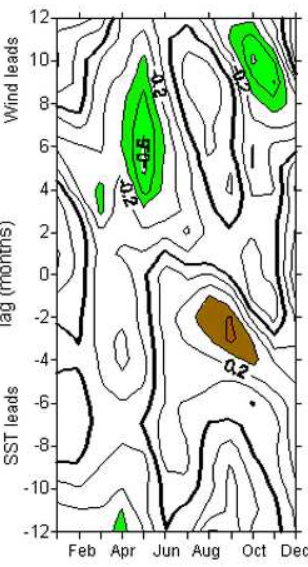

Figure 11. Monthly lagged correlation of SST Nino 3.4 as a function of start month with respect to WPacMJO $O L R$ a) NCEP/NCAR Reanalysis b) LODCA-QTCM experiment Newevap c) LODCA-QTCM -experiment NewFlux d) QTCM (forced mode). Period 1977-2006 for Reanalysis and $108-137$ years of model run. Contour interval is 0.1 . Correlation higher (smaller) than $0.3(-0.3)$ are colored.

ocean warming, which is due to the fact that convection associated with these waves increases as they propagate across the warm ocean.

The coupled model captures the main characteristics of the observed ITV/ENSO relationship, which is promising for further ENSO studies using this model.

It is also demonstrated that the causative relation between ENSO and ITV patterns are strongly dependent on the period under investigation. It is shown that periods of strong ENSO amplitude are characterized by increased activity in both the MJO and the equatorial Rossby waves in the western-central Pacific in spring-summer preceding El Niño. On the other hand, the seasonal relationship between ENSO and ITV exhibits a significantly different characteristic during periods of low ENSO amplitude. In particular, prior to ENSO peak, the MJO and Rossby wave signal is weaker and shifted to the eastern Pacific while during the subsequent year the MJO activity is maintained during the whole year. Interestingly the response in the atmosphere Kelvin waves is restricted to the season (boreal spring) following the mature ENSO phase, traducing the persistence of warm mean conditions.

Overall our study provides material for the interpretation of the observed change in ENSO characteristics in recent years. In particular, it has been noticed that the occurrence of the non-conventional El Niño (i.e. Central Pacific El Niño) has been increasing since 1990 [4, 41, 87], which has been argued to be related to the mean state changes in the tropical Pacific and ENSO feedback processes [87]. Our results indicate that such trends could also be re- lated to changes in the ITV/ENSO relationship. This is the topic of current research.

\section{Acknowledgements}

We are grateful to Prof. David Neelin for providing the QTCM model and Dr. Matthew Wheeler for providing the codes for space-time spectral analysis as well as for discussions on the calculation of the seasonal dependence of the MJO with ENSO. Prof. S.-I. An is also acknowledged for fruitful discussions. The investigation was funded by RFBR (Russian foundation for basic researches) grants No. 08-05-00243 and international grant No.0805-92550 CNRS-RFBR.

\section{References}

[1] An S.I., Wang B., Interdecadal change of the structure of the ENSO mode and its impact on the ENSO frequency. J. Climate, 2000, 13, 2044-2055

[2] An S.I., Jin F.F., Nonlinearity and asymmetry of ENSO. J. Climate, 2004, 17, 2399-2412

[3] An S.I., Interdecadal changes in the El Niño-La Niña asymmetry, Geophys. Res. Lett., 2004, 31, L23210

[4] Ashok K., Behera S.K., Rao S.A., Weng H., Yamagata T., El Niño Modoki and its possible teleconnection. J. Geophys. Res., 2007, 112, Cl 1007, doi: 10.1029/2006JC003798 
[5] Batstone C., Hendon H.H., Stochastic variability associated with ENSO and the role of the MJO. J. Climate, 2005, 18, 1773-1789

[6] Berbery E.H., Nogue's-Paegle J., Intraseasonal interactions between the Tropics and Extratropics in the Southern Hemisphere. J. Atmos. Sci., 1993, 50, 1950 1965

[7] Bergman J.W., Hendon H.H., Weickmann K.M., Intraseasonal Air-Sea Interactions at the Onset of El Niño. J. Climate, 2001, 14, 1702-1719

[8] Betts A.K., Miller M. I, A New Convective Adjustment Scheme. Part II: Single Column Tests Using GATE Wave, BOMEX, ATEX, and Arctic Air-Mass Data Sets," Q. J. R Meteorol. Soc., 1986, 112, 693709

[9] Cibot C., Maisonnave E., Terray L., Dewitte B., Mechanisms of tropical Pacific interannual-to-decadal variability in the ARPEGE/ORCA global coupled model. Clim. Dynam., 2005, 10.1007/s003 82-0040513-y

[10] Shu C., Quasi-biennial winds in the far western equatorial Pacific phase-locking El Niño to the seasonal cycle. Geophys. Res. Lett, 2000, 27, 771-774

[11] Cobb K., Charles C., Cheng H., Edwards, R., El Niño/Southern Oscillation and tropical Pacific climate during the last millennium. Nature, 2003, 424, 272-276

[12] de Boer Montegut C, Mardec G, Fisher A.S, Lazar A, ludicone $D$ Mixed layer depth over the global ocean: an examination of profile data and a profile based climatology. J. Geophys. Res. 2004, 109:C12003. doi:10.1029/2004JC002378

[13] Dewitte B., Gushchina D.Yu., duPenhoat Y., Lakeev S., On the importance of subsurface variability for ENSO simulation and prediction with intermediate coupled models of the Tropical Pacific: A case study for the 1997-1998 El Niño, Geophys. Res .Lett., 2002, 29, doi: 10.1029/2002 JC001498

[14] Dewitte B., Gushchina D., A Mechanism of ENSO modulation in an hybrid coupled model of the tropical Pacific, In: duPenhoat Y., Kislov A. (Eds), Climate variability in the tropical Pacific: mechanisms, modeling and observations, MAKS Press, Moscow, 2010, 96-110

[15] Dewitte B., Purca S., Illig L., Renault B., Giese, Low frequency modulation of the intraseasonal equatorial Kelvin wave activity in the Pacific ocean from SODA: 1958-2001. J. Climate, 2008, 21, 6060-6069

[16] Dewitte B., Sensitivity of an intermediate oceanatmosphere coupled model of the tropical Pacific to its oceanic vertical structure. J. Climate, 2000, 13, 2363-2388
[17] Dunkerton T.J., Baldwin M.P., Observation of 3-6 day meridional wind oscillations over the Tropical Pacific, 1973-1992: Horizontal structure and propagation. J. Atmos. Sci., 1995, 52, 1585-1601

[18] Eisenman L., Yu L., Tziperman E., Westerly wind bursts: ENSO's tail rather than the dog? J. Climate, 2005, 18, 5224-5238

[19] Gill A., Some simple solutions for heat-induced tropical circulation. Quart. J. Roy. Meteor. Soc, 1980, 106, 447-462

[20] Gribble-Verhagen L., Roundy P.E., Analysis of apparent coupling between an oceanic Kelvin wave and atmospheric convection during the winter of 1986/87, J. Climate, 2010, 23, 6352-6364

[21] Gushchina D., Dewitte B., Seasonal relationship between intraseasonal atmospheric tropical variability and ENSO in a tropical Pacific coupled model. In: duPenhoat Y. Kislov A. (Eds), Climate variability in the tropical Pacific: mechanisms, modeling and observations. MAKS Press, Moscow, 2010, 111-140

[22] Gushchina D.Yu., Dewitte B., Interannual Climate Variability and Teleconnections in a QuasiEquilibrium Tropical Circulation Model. Izvestia Akademia Nauk, Fizika Atmosphery and Okeana, 2005, 41, No. 4, 393-417 [Translated from Izv. Akad. Nauk, Fiz. Atmos. Okeana, Vol. 41, No. 4, 2005, 435463]

[23] Gushchina D.Yu., Dewitte B., Petrosyants M.A., Coupled Atmosphere-Tropical Pacific Model: Forecasting the 1997-1998 El Niño-Southern OsciUation, Izv. Akad. Nauk, Fiz. Atmos. Okeana 2000, 36, 581-604 [Izv., Atmos. Ocean. Phys. 2000, 36, 533-554]

[24] Gushchina D., Dewitte B. and Illig S., Remote ENSO forcing versus local air-sea interaction in QTCM: a sensitivity study to intraseasonal variability. $A d-$ vances in Geosciences, 2006, 6, 289-297, SRef-ID: 1680-7359/adgeo/2006-6-289

[25] Gushchina D.Yu., Petrossiants M.A., Semenov E.K. The empirical model of tropical troposphere circulation during the event El Niño Southern OsciUation. Part 1. The analysis of circulation characteristics evolution under ENSO conditions. Russian meteorology and hydrology, 1997, No. 2, 4-28

[26] Gushchina D.Yu., Dewitte B., Korkmazova S., Intraseasonal variability in the tropical troposphere and its simulation by the atmospheric model of intermediate complexity. Meteorologya y hydrologya, 2010, No. 4, 11-35

[27] Hayashi Y., Golder D.G., Tropical intraseasonal oscillation appearing in the GFDL general circulation model and FGGE data. Part I. Phase propagation. J. Atmos. Sci., 1986, 43, 3058-3067 
[28] Hayashi Y., Sumi A., The 30-40 day oscillation simulated in an "aqua planet" model. J. Meteor. Soc. Japan., 1986, 64, 451-466

[29] Hendon H.H., Wheeler M.C., Zhang C., Seasonal Dependence of the MJO-ENSO Relationship. J. Climate, 2007, 20, 531-543

[30] Hendon H.H., Zhang C., Glick I., Interannual variation of the Madden-Julian oscillation during austral summer. J. Climate, 1999, 12, 2538-2550

[31] Hendon H.H., Liebmann B., Glick J.D., Oceanic Kelvin waves and the Madden-Julian Oscillation. J. Atmos. Sci., 1998, 55,88-101

[32] Kalnay E., Kanamitsu M., Kistler R., Collins W., Deaven D., Gandin L., Iredell M., Saha S., et al., The NCEP/NCAR 40-Year Reanalysis Project. Buli. Amer. Meteor. Soc, 1996, 77, 437-471

[33] Kao H.Y., Yu J.Y., Contrasting Eastern-Pacific and Central-Pacific types of ENSO. J. Climate, 2009, 22, 615-632

[34] Kessler W.S., McPhaden M.J., Weickmann K.M., Forcing of intraseasonal Kelvin waves in the equatorial Pacific. J. Geophys. Res., 1995, 100, 10613-10631

[35] Kessler W.S., Kleeman R., Rectification of the Madden-Julian oscillation into the ENSO cycle. J. Climate, 2000, 13, 3560-3575

[36] Kiladis G.N., Straub K.H., Haertel P.T., Zonal and vertical structure of the Madden-Julian Oscillation. J. Atmos. Sci., 2005, 62, 2790-2809

[37] Kug J.S., Jin F.F., An S.L, Two types of El Niño events: cold tongue El Niño and warm pool El Niño. J. Climate, 2009, 22, 1499-1515

[38] Larkin N.K., Harrison D.E., Global seasonal temperature and precipitation anomalies during $\mathrm{El} \mathrm{Niño}$ autumn and winter. Geophys. Res. Lett., 2005, 32, L13705, doi: 10.1029/2005GL02273 8

[39] Lau W.K.M., El Niño Southern Oscillation connection. In: Lau W. K. M., Waliser D. E. (Eds), Intraseasonal Variability in the Atmosphere-Ocean Climate System, Praxis Publishing, 2005, 71-300

[40] Lau N. C, Held I.M., Neelin J.D., The Madden-Julian oscillations in an idealized general circulation model. J. Atmos. Sci., 1988, 45, 3810-3831

[41] Lee T., McPhaden M.J., Increasing intensity of El Niño in the central-equatorial Pacific, Geophys. Res. Lett., 2010, 37, L14603, doi: 10.1029/2010GL044007

[42] Lengaigne M., Boulanger J.P., Menkes C., Masson S., Madec G., Delecluse P., Ocean response to the March 1997 Westerly Wind Event. J. Geophys. Res., 2002, 107, 8015, doi: 10.1029/2001JC000841

[43] Liebmann B., Hendon H.H., Glick J. D., The relationship between $\mathrm{t}$ tropical cyclones of the western Pacific and Indian Oceans and the Madden-Julian oscilla- tion. J. Meteor. Soc. Japan, 1994,72,401-411

[44] Lin J.W.B., Neelin J.D., Zeng N., Maintenance of tropical intraseasonal variability: Impact of evaporationwind feedback and mid-latitude storms. J. Atmos. Sci., 2000, 57, 2793-2823

[45] Lin J.L., Kiladis G.N., Mapes B.E, Weickmann K.M, Sperber K.R., Lin W., Wheeler M.C, Schubert S.D., Del Genio A., Donner L., Emori S., Gueremy J.F., Hourdin F., Rasch P., Roeckner E., Scinocca J.F., Tropical intraseasonal variability in 14 IPCC AR4 climate models Part I: convective signals. J. Climate, 2006, 19, 2665-2690, doi:10.1175/JCLI3735.1

[46] Madden R., Julian P., Description of global-scale circulation cells in the tropics with a 40-50 day period. J. Atmos. Sci., 1972, 29, 1109-1123

[47] Majda A.J., Biello J.A., A multi-scale model for tropical intraseasonal oscillations. Proc. Natl. Acad. Sci., 2004, 101, 4736-4741

[48] Majda A.J., Biello J., A New Multi-Scale Model for the Madden-Julian Oscillation. J. Atmos. Sci., 2005, 62, 1694-1721

[49] Maloney E.D., Hartmann D.L., The Madden-Julian Oscillation, Barotropic Dynamics, and North Pacific Tropical Cyclone Formation. Part I: Observations. J. Atmos. Sci., 2001, 58, 2545-2558

[50] Matthews A.J., Kiladis G.N., A model of Rossby waves linked to submonthly convection over the eastern tropical Pacific. J. Atmos. Sci., 2000, 57, No.23, 37853798

[51] McPhaden M.J., Genesis and evolution of the 199798 El Niño. Science, 1999, 283, 950-954

[52] McPhaden M.J., Zhang X., Hendon H.H., Wheeler M.C., Large scale dynamics and MJO forcing of ENSO variability. Geophys. Res. Lett., 2006, 33, L16702, doi:10.1029/2006GL026786

[53] Moncrieff M.W., Analytic representation of the largescale organization of tropical convection. J. Atmos. Sci., 2004, 61, 1521-1538

[54] Moore A.M., Kleeman R., Stochastic forcing of ENSO by the intraseasonal oscillation. J. Climate, 1999, 12, 1199-1220

[55] Neelin, J.D., Zeng N., A quasi-equilibrium tropical circulation model-formulation, J. Atmos. Sci., 2000, 57, 1741- 1766

[56] Picaut J., loualalen M., Delcroix T., Masia F., Murtugudde R, Vialard J., The oceanic zone of convergence on the eastern edge of the Pacific warm pool: A synthesis of results and implications for El NiñoSouthern Oscillation and biogeochemical phenomena. J. Geophys. Res., 2001, 106,2363-2386

[57] Rasmusson E., Carpenter T., Variations in the tropical sea surface temperature and surface wind fields as- 
sociated with the Southern Oscillation/El Niño. Mon. Wea. Rev., 1982, 110, 354-384

[58] Roundy P.E., Kiladis G. N, Observed relationship between oceanic Kelvin waves and atmospheric forcing. J. Climate, 2006, 19, 5253-5272

[59] Roundy P.E., Kravitz I.R., The association of the evolution of intraseasonal oscillations to ENSO phase. J. Climate, 2009, 22, 381-395

[60] Salby M.L., Hendon H.H., Intraseasonal behavior of clouds, temperature, and motion in the Tropics. J. Atmos. Sci., 1994, 51, 2207-2224

[61] Schubert S., Dole R., Dool H.V.D., Suarez M., Waliser D., Prospects for improved forecasts of weather and short-term climate variability on subseasonal (2 week to 2 month) time scales. In: Proceedings of the workshop, Mitchellville, 2002, MD, NASA/TM 2002 104606, 23, 71

[62] Seiki A., Takayabu Y.N., Yoneyama K., Sato N, Yoshizaki M.. The oceanic response to the MaddenJulian oscillation and ENSO. SOLA, 2009, 5, 093 096, doi:10.2151/sola.2009-024

[63] Seiki A., Takayabu Y.N. Westerly wind bursts and their relationship with intraseasonal variations and ENSO. Part I: Statistics, Mon. Wea. Rev., 2007, 135, 3325D3345

[64] Seiki, A., Takayabu Y.N .Westerly wind bursts and their relationship with intraseasonal variations and ENSO. Part II: Energetics over the Western and Central Pacific, Mon. Wea. Rev., 2007, 135,334603361

[65] Shinoda T., Hendon H.H., Upper-ocean heat budget in response to the Madden-Julian oscillation in the western equatorial Pacific. J. Climate, 2001, 14, 41474165

[66] Shinoda T., Roundy P.E., Kiladis G.N. Variability of intraseasonal Kelvin waves in the equatorial Pacific Ocean. J. Phys. Oceanogr., 2008, 38, 921-944

[67] Slingo J.M., Sperber K.R. and 22 others, Intraseasonal oscillations in 15 atmospheric general circulation models: Results from an AMIP diagnostic subproject. Climate Dyn., 1996, 12, 325-357

[68] Slingo J.M., Rowel D.P., Sperber K.R., On the predictability of the interannual behavior of the MaddenJulian Oscillation and its relationship with El Niño. Quart. J. Roy. Meteor. Soc, 1999, 125, 583-609

[69] Straub K.H., Kiladis G.N., The observed structure of convectively coupled Kelvin waves: Comparison with simple models of coupled wave instability. J. Atmos. Sci., 2003, 60, 1655-1668

[70] Takayabu Y.N., Iguchi T., Kachi M., Shibata A., Kanzawa H., Abrupt termination of the 1997-98 El Niño in response to a Madden-Julian oscillation. Nature, 1999, 402, 279-282
[71] Takayabu Y.N., Large-scale cloud disturbances associated with equatorial waves. Part II: Westward propagating inertio-gravity waves. J. Meteor. Soc. Japan, 1994, 72, 451-465

[72] Takayabu Y.N., Large-scale cloud disturbances associated with equatorial waves. Part I: Spectral features of the cloud disturbances. J. Meteor. Soc. Japan, 1994, 72, 433-448

[73] Takayaby Y.N., Nitta T., 3-5 day period disturbances coupled with convection over the tropical Pacific Ocean. J. Meteor. Soc. Japan, 1993, 71, 221-246

[74] Torrence C., Compo G.P., A Practical Guide to Wavelet Analysis. Bull. Amer. Meteor. Soc., 1998, 79, 61-78

[75] Trenberth K., Shea D.J., On the evolution of the Southern Oscillation, Mon. Weath. Rev., 1987, 115, 3078-3096

[76] Waliser D.E., Lau K.M., Stern W., Jones C., Potential Predictability of the Madden-Julian Oscillation, Buli. Amer. Meteor. Soc, 2003, 84, 33-50

[77] Waliser D.E., Predictability and Forecasting. In: Lau W.K.M., Waliser D.E. (Eds.), Intraseasonal Variability of the Atmosphere-Ocean Climate System, , Springer, Heidelberg, Germany, 2005

[78] Wang G., Hendon H.H., Sensitivity of Australian rainfall to inter-El Niño variations. J. Climate, 2007, 20, 4211-4226

[79] Weickmann K.M., El Niño Southern Oscillation and the Madden-Julian (30-60 day) oscillation during 1981-82. J.Geophys. Res., 1991, 96, 3187-3196

[80] Weickmann K.M., Lussky G.R., Kutzbach J.E., Intraseasonal (30-60 day) fluctuations of outgoing longwave radiation and $250 \mathrm{mb}$ streamfunction during northern winter. Mon. Wea. Rev., 1985, 113, 941-961

[81] Wheeler M.C., Kiladis G.N., convectively coupled equatorial waves: Analysis of clouds and temperature in the wavenumber-frequency domain. J. Atmos. Sci., 1999, 56, 374-399

[82] Wheeler M., Weickmann K.M., Real-time monitoring and prediction of modes of coherent synoptic to intraseasonal tropical variability. Mon. Wea. Rev., 2001, 129, 2677-2694

[83] Wheeler M., Convectively-coupled equatorial waves. Ph.D. Thesis, University of Colorado, Boulder, USA, 1998

[84] Wheeler M., Kiladis G.N., Webster P., Large-Scale Dynamical Fields Associated with Convectively Coupled Equatorial Waves. J. Atmos.Sci., 2000, 57, 613640

[85] Wheeler M.C., McBride J.L., Australian-Indonesian monsoon. In: Lau W.K.M., Waliser D.E. (Eds.), Intraseasonal Variability in the Atmosphere-Ocean Cli- 
mate System., Praxis Pubhshing, 2005, 125-173

[86] Yasunari T., Cloudiness fluctuations associated with the northern hemisphere summer monsoon. J. Meteor. Soc. Japan, 1979, 57, 227-242

[87] Yeh S.W., Kug S.J., Dewitte B., Kwon M.H., Kirtman B.P. , Jin F.F., El Niño in a changing climate, Nature, 2009, 461, 511-514

[88] Yu L., Weller R A., Liu W.T., Case analysis of a role of ENSO in regulating the generation of westerly wind bursts in the Western Equatorial Pacific. J. Geophys. Res., 2003, 108, 3128, doi:10.1029/2002JC001498

[89] Zavala-Garay, J., Zhang C., Moore A.M., Kleeman R., The linear response of ENSO to the Madden-Julian oscillation. J. Climate, 2005, 18, 2441-2459

[90] Zebiak S.E., Cane M.A., A model El Niño-Southern Oscillation, Mon. Weather Rev., 1987, 115,22622278,.

[91] Zeng N., Neelin J.D., Chou, C. The first quasiequilibrium tropical circulation model implementation and simulation. J. Atmos. Sci., 2000, 57, 1767-1796

[92] Zhang C., Dong M., Seasonality in the MaddenJulian oscillation. J. Climate, 2004, 17, 3169-3180

[93] Zhang C., Gottschalck J., SST Anomalies of ENSO and the Madden-Julian oscillation in the equatorial Pacific. J. Climate, 2002, 15, 2429-2445 